Article

\title{
Investigation of the Atmospheric Boundary Layer Height Using Radio Occultation: A Case Study during Twelve Super Typhoons over the Northwest Pacific
}

\author{
Jiaqi Shi ${ }^{1,2}$, Kefei Zhang ${ }^{1,2,3, *}$, Suqin Wu ${ }^{1,2}$, Shuangshuang Shi ${ }^{1,2}$ and Zhen Shen ${ }^{1,2}$ \\ 1 Jiangsu Key Laboratory of Resources and Environmental Information Engineering, \\ China University of Mining and Technology, Xuzhou 221116, China; shijq@cumt.edu.cn (J.S.); \\ suqin_wu@cumt.edu.cn (S.W.); shshshi@whu.edu.cn (S.S.); shenzhen@cumt.edu.cn (Z.S.) \\ 2 School of Environment Science and Spatial Informatics, China University of Mining and Technology, \\ Xuzhou 221116, China \\ 3 Satellite Positional for Atmosphere, Climate and Environment (SPACE) Research Centre, \\ Royal Melbourne Institute of Technology (RMIT) University, Melbourne, VIC 3001, Australia \\ * Correspondence: profkzhang@cumt.edu.cn; Tel.: +86-186-1167-3810
}

check for updates

Citation: Shi, J.; Zhang, K.; Wu, S.; Shi, S.; Shen, Z. Investigation of the Atmospheric Boundary Layer Height Using Radio Occultation: A Case Study during Twelve Super Typhoons over the Northwest Pacific. Atmosphere 2021, 12, 1457. https:// doi.org/10.3390/atmos12111457

Academic Editors: Eric A. Hendricks and Victor Ivanovich Zakharov

Received: 16 September 2021

Accepted: 2 November 2021

Published: 3 November 2021

Publisher's Note: MDPI stays neutral with regard to jurisdictional claims in published maps and institutional affiliations.

Copyright: (c) 2021 by the authors. Licensee MDPI, Basel, Switzerland. This article is an open access article distributed under the terms and conditions of the Creative Commons Attribution (CC BY) license (https:// creativecommons.org/licenses/by/ $4.0 /)$.

\begin{abstract}
This study investigated the relationship between variations in the atmospheric boundary layer height $(\mathrm{ABLH})$ and typhoons over the Northwest Pacific using global navigation satellite system (GNSS) radio occultation (RO) data during the local summer typhoon season (July-October in the Northern Hemisphere) from 2007 to 2020. The minimum gradient of refractivity derived from COSMIC and COSMIC-2 was used to determine the ABLH. The RO profiles were co-located with the position of a typhoon track base within a $600 \mathrm{~km}$ space window and different time windows. ABLH climatology with a $2.5^{\circ} \times 2.5^{\circ}$ horizontal resolution was developed, which can be used to obtain the interpolated mean ABLH at any target position. The mean ABLH at the central typhoon position in a specific year was compared with the results interpolated from the climatology of the same location (excluding the year in which the investigated typhoon occurred). In this paper, the results indicate that the ABLH is lower in the vicinity of typhoons relative to the undisturbed atmosphere by a significant amount, and that the reduction in ABLH ranges from $0.13 \mathrm{~km}$ to $0.39 \mathrm{~km}$. It was also found that the ABLH was negatively correlated with wind speed, and that the mean correlation coefficient was -0.607 . Moreover, similar results can be obtained via the $\mathrm{RO}$ water vapor partial pressure profile compared to the refractivity results.
\end{abstract}

Keywords: COSMIC; COSMIC-2; GNSS RO; typhoon track; atmospheric boundary layer height

\section{Introduction}

The atmospheric boundary layer (ABL) is the layer closest to the Earth's surface, where turbulent processes often dominate the vertical redistribution of sensible heat, momentum, moisture, and aerosols [1]. It plays an important role in the energy transport processes of tropical cyclones, regulating the radial and vertical distributions of momentum and enthalpy, which are closely related to storm development and intensification [2-4]. The atmospheric boundary layer height (ABLH) is a crucial parameter of the ABL, which is usually incorporated into the parameterization of ABLH-related physical processes [5]. The structure of the ABL can be complex and variable, and the ABLH is commonly used to characterize the extent of vertical mixing within the ABL and the level at which exchange with the free troposphere occurs [6].

The ABL is complex, and there are different methods for defining and identifying it. In numerical models, the bulk Richardson number has been widely used to determine the ABLH in ABLH parameterization schemes [5,7,8]. The ABLH is usually taken as the height at which the magnitude of the turbulence parameter becomes much smaller ( $95 \%)$ than that at the surface layer when the vertical profiles of turbulent intensity and/or flux are 
measured, and it can be defined via the height of the temperature inversion layer when there are no turbulence data available due to unstable conditions [9]. Moreover, the measurement of the vertical gradient of virtual potential temperature with a threshold and the parcel method can be used to identify the ABLH when flux data are not available [10-12].

Tropical cyclones generally form over tropical and subtropical ocean regions, and are destructive natural disasters [13]. Tropical cyclones over the Atlantic and the Northeast Pacific are named hurricanes, and tropical cyclones over the Northwest Pacific are named typhoons. Previous studies have shown the characteristics of the tropical cyclone boundary layer. Zhang et al. showed that both the kinematic and thermodynamic boundary layer height scales tend to decrease with a decreasing wind radius [14]. Smith et al. proved that the loss of absolute angular momentum in the tropical cyclone boundary layer results in a gradient force, where a reduction in total wind due to friction deflects flow toward the storm center [15]. Kepert et al. and Bryan et al. studied the mechanisms of dry static stability in the lowest $1-2 \mathrm{~km}$ of a tropical cyclone, using the axisymmetric tropical cyclone model [16,17]. There is a clear separation between the dynamical boundary layer height, defined by the height of the inflow layer and the maximum tangential wind speed, and the thermodynamic boundary layer height, defined by the mixed layer depth. Furthermore, the asymmetric structure of the hurricane boundary layer in relation to the environmental vertical wind shear has been investigated under hurricane conditions $[5,9]$. The relationship between the ABLH kinematic and thermodynamic asymmetries to convection was reverberated in a case study on the evolution of Hurricane Edouard in 2014 [18,19]. Additionally, a TC's structure is also modulated by the ABL. The interplay between a TC's primary and secondary circulations is imperative to changes in storm intensity. Previous studies have proven that ABL is closely related to typhoons [20,21].

Multiple techniques have been used to study tropical cyclone ABLH in previous studies. Measurement can be affected by safety issues under tropical cyclone conditions. The radiosonde data were used to estimate the ABLH via the parcel method [11,22,23]. A GPS dropsonde is widely used to estimate the scales of tropical cyclone ABLH; it can collect the atmospheric profiles of pressure, temperature, relative humidity, and horizontal winds, with a vertical sampling resolution of $\sim 7 \mathrm{~m}$ [24]. The wavelet covariance transform (WCT) technique was used to determine the global distribution of the top of the ABL from COSMIC RO measurements [25]. The dataset of three-dimensional winds, measured deep into the hurricane boundary layer with a $\sim 200 \mathrm{~m}$ horizontal and $30 \mathrm{~m}$ vertical resolution, provided by the Imaging Wind and Rain Airborne Profiler (IWRAP), is helpful for investigating the characteristics of the ABLH [26,27].

Global navigation satellite system (GNSS) radio occultation (RO) is a new and effective technique for atmospheric sounding that has been introduced in the last two decades [28-31]. The Constellation Observing System for Meteorology, Ionosphere, and Climate (COSMIC) mission has accumulated long-term stable observation data [32]. Following the success of COSMIC, COSMIC-2 was launched on 25 June 2019, providing higher-quality RO data than COSMIC [33-35]. The RO data have been widely used in studies of the ABLH and of the atmospheric parameters under tropical cyclone conditions [1,36-39]. Xie et al. used $\mathrm{RO}$ data to detect a wide range of ABLH variations, and concluded that the European Center for Medium-Range Weather Forecasts (ECMWF) analysis method systematically underestimates the ABLH [40]. Ao et al. assessed global ABLH climatology using RO refractivity and water vapor pressure data and compared the difference between the results obtained from RO and ERA-Interim [1]. Basha et al. also established global ABLH climatology based on multi-satellite GPS RO observations, and showed the seasonal variation in globally averaged ABLH over the land and ocean at different latitude bands [41]. Biond et al. and Lasota et al. characterized the thermal structure near TCs and the distribution of atmospheric parameters using RO datasets $[37,39]$. The $\mathrm{RO}$ data were confirmed to be valuable for studies on the atmosphere under severe weather conditions [42].

Previous studies have shown the characteristics of different atmospheric parameters and the ABLH during tropical cyclones [36]. However, limited by the amount of RO 
data, continuous variations in the ABLH have not been widely studied. In this study, the refractivity data from COSMIC and COSMIC-2 were used to study the variation in the ABLH during some super typhoons over the Northwest Pacific region. Based on the test results for a $12 \mathrm{~h}$ time window, the continuous variations in ABLH along the paths of typhoons were investigated within a $36 \mathrm{~h}$ time window.

This paper is structured as follows: Section 2 introduces the data and methods used for constructing ABLH climatology and for co-locating a typhoon's path with the RO profiles. Section 3 shows the test results, and the discussion and conclusion are given in Section 4.

\section{Data and Methods}

\subsection{RO Data}

Atmospheric RO profile datasets, including moisture information (denoted as wetPrf for COSMIC and wetPf2 for COSMIC-2, hereafter) provided by the COSMIC Data Analysis and Archive Centre (CDAAC), were used as the test datasets in this study. Note that gridded analysis or a short-term forecast are used to distinguish between the contributions of pressure, temperature, and moisture to refractivity. The wetPrf file is interpolated to $100 \mathrm{~m}$ heights, while the wetPf2 file is interpolated to $50 \mathrm{~m}$ heights from 0 to $20 \mathrm{~km}$ and $100 \mathrm{~m}$ heights from $20 \mathrm{~km}$ to $60 \mathrm{~km}$. It should also be noted that the wetPrf dataset was divided into reprocessed and post-processed datasets according to data processing methods, corresponding to the 22 April 2006 to 30 April 2014 and the 1 May 2014 to 1 May 2020 periods, respectively. The wetPf2 dataset for 1 July 2020 to 31 October 2020 was also used in this study, which is a near-real-time operational dataset. More specifically, since the region of interest in this study is the Northwest Pacific, where typhoons mainly occur in summer, the above datasets were investigated in the local summer period (from July to October). Both COSMIC and COSMIC-2 were designed on the basis of GNSS data acquired with open-loop (OL) tracking technology, which was developed and tested on SAC-C. In addition to increasing the number of RO events, OL tracking is crucial for ABL studies because it provides much more accurate measurements deeper into the lower troposphere and the ABL [43].

COSMIC-2, with its higher signal-to-noise ratio (SNR), is expected to increase the utility of the ray at lower altitudes [33,44,45]. Because of its lower inclination orbit $\left(24^{\circ}\right)$, COSMIC-2 can provide 4000-5000 RO profiles per day, most of which are located within $\pm 45^{\circ}$ latitudes. Figure 1 shows the distribution and the lowest detection height of the RO profiles derived from COSMIC on 15 October 2008 and COSMIC-2 on 15 October 2020 in the left column, while the statistical histograms are shown in the right column. The dots in Figure 1 indicate RO profiles, and the different colors represent the lowest detection heights for each profile. Figure 1 illustrates that the quantity of data in COSMIC- 2 is about double that in COSMIC, and that the mean of the lowest detection height of COSMIC-2 is $0.41 \mathrm{~km}$ lower than that of COSMIC. Moreover, the distribution of RO profiles in COSMIC-2 is more suitable for studies on tropical cyclones. However, considering that COSMIC-2 was launched in October 2019, it has only been used to study typhoons in 2020. 

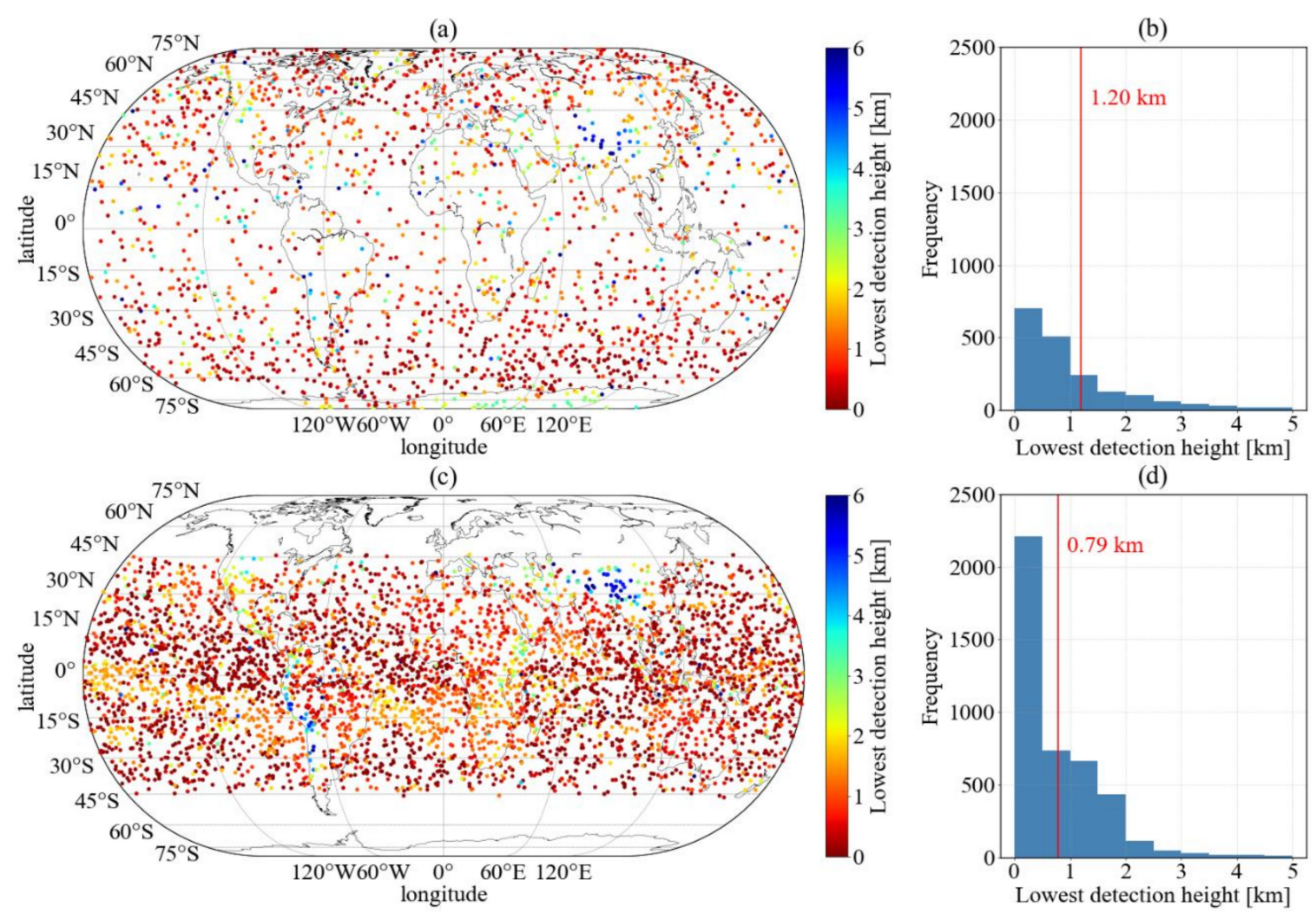

Figure 1. The location of RO profiles (a) for COSMIC on 15 October 2008 and (c) COSMIC-2 on 15 October 2020. (b) and (d) show the statistical histograms of the lowest detection height corresponding to (a) and (c), respectively. The red vertical line represents the mean of the lowest detection height.

\subsection{Typhoon Track}

The typhoon track dataset (downloaded from the Zhejiang Water Provincial Resources Department website, China) includes the longitude, latitude, local time, wind speed, wind direction, and typhoon intensity at the typhoon's central position. As the typhoon's central position moves, the time interval corresponding to its current and future positions varies, which negatively correlates with wind speed. The minimum time interval is usually one hour. The six typhoon scales (or stages), based on wind speed, defined by the China Meteorological Administration (CMA), are shown in Table 1. It should be noted that if a wind speed is equal to $17.1 \mathrm{~m} / \mathrm{s}$, it belongs to a TS.

Table 1. Typhoon scales/stages, based on wind speed (in $\mathrm{m} / \mathrm{s}$ ), defined by the CMA.

\begin{tabular}{ccccccc}
\hline Scale & Tropical Depression & Tropical Storm & Severe Tropical Storm & Typhoon & Severe Typhoon & Super Typhoon \\
\hline Abbreviation & TD & TS & STS & TY & STY & Super TY \\
Wind speed & $10.8-17.1$ & $17.1-24.4$ & $24.4-32.6$ & $32.6-41.4$ & $41.4-51$ & $\geq 51$ \\
\hline
\end{tabular}

In this study, nine typhoons that occurred during the 11-year period of 2007-2018, and three that occurred during 2020, were selected for testing, because both of the periods offer reasonable quantities of COSMIC data. The criteria for the selection of a typhoon event are as follows: (1) the typhoon must have been a super TY, i.e., the maximum speed must reach above $51 \mathrm{~m} / \mathrm{s}$ for a sufficient result; (2) no other typhoons can have affected the typhoon of interest, i.e., the typhoon must have been as far as possible, both temporally and spatially, from other typhoons. The first criterion can be easily met, but the second is difficult. This is because a super TY generally lasts for 5-15 days and has a large wind circle radius, meaning that the area covered by the track of the typhoon is also large, which in turn increases the chance of an overlap between this typhoon and other typhoons in both time and space. This overlap can be translated into the effect of other typhoons. In this 
study, after all the typhoons that occurred in the local summer period over the Northwest Pacific region in the periods of 2007-2018 and 2020 were examined, and a sufficient number of associated RO profiles was considered (which can be regarded as the third criterion), twelve typhoons were finally selected for testing. Figure 2 and Table 2 show the information and tracks of each of the twelve typhoons, respectively.
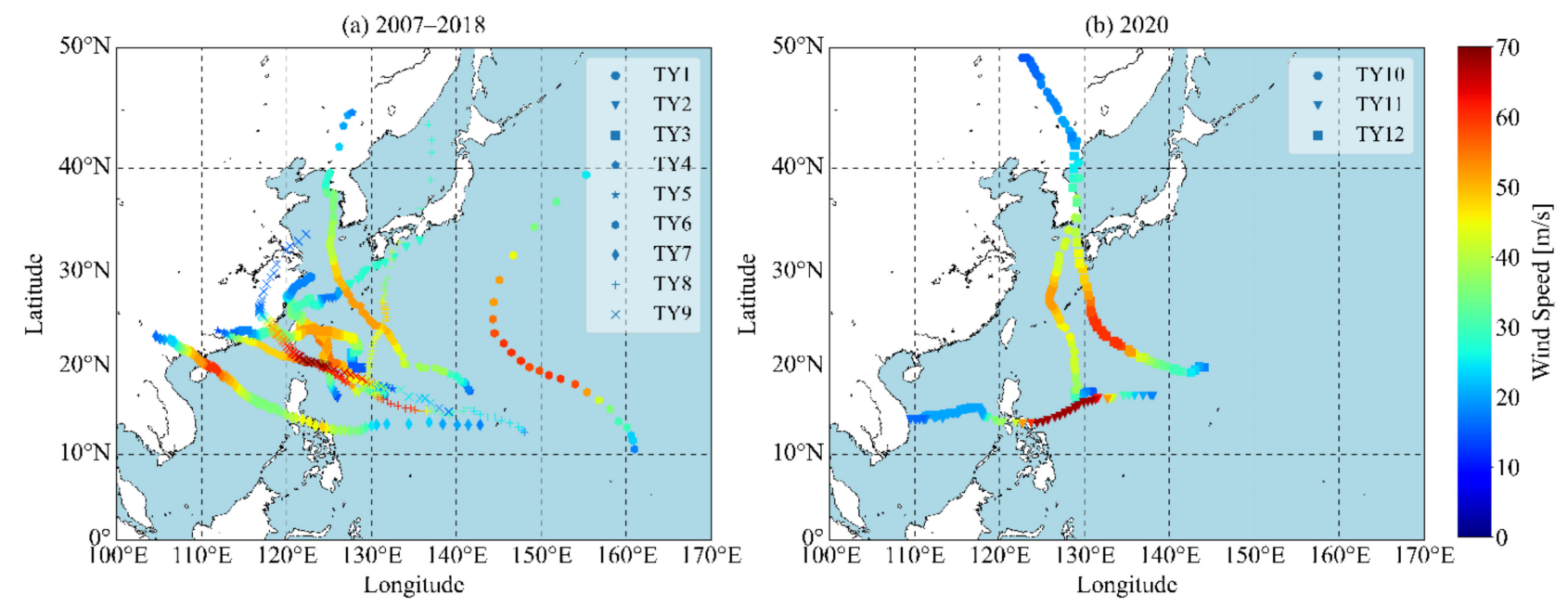

Figure 2. Tracks of the twelve typhoons shown in Table 2. The color bar indicates the wind speed (m/s).

Table 2. Brief information of the twelve typhoons selected in this study.

\begin{tabular}{|c|c|c|c|c|c|}
\hline Typhoon & Time (UTC+8) & $\begin{array}{l}\text { Starting } \\
\text { Position }\end{array}$ & $\begin{array}{l}\text { Ending } \\
\text { Position }\end{array}$ & $\begin{array}{c}\text { Max Wind } \\
\text { Speed }(\mathrm{m} / \mathrm{s})\end{array}$ & $\begin{array}{l}\text { Num. of } \\
\text { Positions }\end{array}$ \\
\hline TY1, Krosa & $2007 / 10 / 02-2007 / 10 / 08$ & $130.0^{\circ} 17.1^{\circ}$ & $122.9^{\circ} 29.5^{\circ}$ & 55 & 103 \\
\hline TY2, Sinlaku & $2008 / 09 / 08-2008 / 09 / 19$ & $126.0^{\circ} 16.4^{\circ}$ & $135.7^{\circ} 33.1^{\circ}$ & 52 & 171 \\
\hline TY3, Fanapi & $2010 / 09 / 15-2010 / 09 / 21$ & $128.8^{\circ} 19.8^{\circ}$ & $113.8^{\circ} 23.6^{\circ}$ & 52 & 97 \\
\hline TY4, Bolaven & $2012 / 08 / 20-2012 / 08 / 29$ & $141.6^{\circ} 17.2^{\circ}$ & $127.7^{\circ} 44.8^{\circ}$ & 52 & 82 \\
\hline TY5, Usagi & $2013 / 09 / 16-2013 / 09 / 23$ & $132.5^{\circ} 17.5^{\circ}$ & $111.9^{\circ} 23.9^{\circ}$ & 60 & 91 \\
\hline TY6, Lekima & $2013 / 10 / 21-2013 / 10 / 26$ & $161.0^{\circ} 10.6^{\circ}$ & $155.3^{\circ} 39.4^{\circ}$ & 60 & 24 \\
\hline TY7, Rammasun & $2014 / 07 / 12-2014 / 07 / 20$ & $142.8^{\circ} 13.4^{\circ}$ & $104.6^{\circ} 23.3^{\circ}$ & 60 & 107 \\
\hline TY8, Halong & $2014 / 07 / 29-2014 / 08 / 11$ & $148.0^{\circ} 12.6^{\circ}$ & $136.7^{\circ} 43.8^{\circ}$ & 62 & 75 \\
\hline TY9, Meranti & $2016 / 09 / 10-2016 / 09 / 16$ & $139.1^{\circ} 14.9^{\circ}$ & $122.3^{\circ} 33.8^{\circ}$ & 70 & 85 \\
\hline TY10, Maysak & $2020 / 08 / 28-2020 / 09 / 04$ & $131.0^{\circ} 17.2^{\circ}$ & $122.7^{\circ} 49.2^{\circ}$ & 52 & 103 \\
\hline TY11, Haishen & $2020 / 09 / 01-2020 / 09 / 08$ & $144.1^{\circ} 19.9^{\circ}$ & $128.5^{\circ} 48.2^{\circ}$ & 60 & 47 \\
\hline TY12, Goni & $2020 / 10 / 29-2020 / 11 / 06$ & $138.1^{\circ} 16.7^{\circ}$ & $109.5^{\circ} 14.0^{\circ}$ & 68 & 124 \\
\hline
\end{tabular}

\subsection{Algorithm for the $A B L H$}

As noted in the introduction, it was confirmed that the ABLH is divided into a dynamic ABLH and a thermodynamic ABLH, and we focus on the latter in this paper [5]. Since the transition from the ABL to the free troposphere is often marked by a significant change in temperature and the water vapor level, the simplest approach for obtaining the ABLH is to identify the altitude at which the maximum change occurs in the atmospheric vertical profile [46]. The definition of the ABLH based on the minimum vertical gradient has been used in previous studies, because the bending angle, refractivity, and water vapor all tend to decrease with height across the ABLH $[47,48]$.

$\mathrm{RO}$ measurements are sensitive to the vertical gradient of refractivity through ray bending and diffraction effects; the highest-level product retrieved from the $\mathrm{RO}$ signals without ancillary data is the refractivity profile [28,49]. The microwave refractivity, $N$, is related to the thermodynamic properties of the atmosphere, according to the following relationship [50,51]:

$$
N=a_{1} \frac{P}{T}+a_{2} \frac{P_{w}}{T^{2}}
$$


where $P$ is the total pressure $(\mathrm{mb}), T$ is the temperature $(\mathrm{K})$, and $P_{w}$ is the water vapor partial pressure $(\mathrm{mb})$, with constants $a_{1}=77.6 \mathrm{~K} / \mathrm{mb}$ and $a_{2}=3.73 \cdot 10^{5} \mathrm{~K}^{2} / \mathrm{mb}$. The refractivity gradient depends on the pressure gradient, temperature gradient, and water vapor pressure gradient. According to Equation (1), the vertical refractivity gradient can be written as:

$$
N^{\prime}=a_{1} \frac{1}{T} P^{\prime}-\left(a_{1} \frac{P}{T^{2}}+2 a_{2} \frac{P_{w}}{T^{3}}\right) T^{\prime}+a_{2} \frac{P_{w}^{\prime}}{T^{2}} \equiv N_{P}^{\prime}+N_{T}^{\prime}+N_{w}^{\prime}
$$

where $N^{\prime} \equiv d N / d z$ and $d z$ are the increments in altitude. According to Equation (2), the RO refractivity gradient depends closely on both the temperature and water vapor pressure gradients. Moreover, in combination with the $\mathrm{RO}$ inversion algorithm, the refractivity gradient is a better choice because it makes fewer assumptions in its derivation compared to water vapor pressure, which depends on refractivity as well as a first-guess background and the $1 \mathrm{D}$-Var retrieval process.

Given the limitation of an insufficient lowest detection height, the topographical factor needs to be considered. In this study, data pre-processing for RO profiles was performed for the examination of the lowest effective detection height of the RO profiles. If an $\mathrm{RO}$ profile's lowest effective detection height was less than $0.5 \mathrm{~km}$ over the ocean or $1.0 \mathrm{~km}$ over land, it would be selected. Then, the selected profiles were interpolated into $10 \mathrm{~m}$ height layers using the cubic spline interpolation method for calculating the vertical $\mathrm{N}$ gradient from Equation (3):

$$
N_{i}^{\prime}=\frac{N_{i+1}-N_{i+1}}{z_{i+1}-z_{i+1}}
$$

where $i$ is the index of the interpolated data layer. If $i_{0}$ is the index of the layer at which $N_{i}{ }^{\prime}$ reaches its minimum, in this case, the altitude of the layer corresponding to $i_{0}$ is the refractivity-based $\mathrm{ABLH}$, according to Equation (4):

$$
A B L H=H_{i_{0}}
$$

Figure 3 illustrates the refractivity, water vapor pressure, and their gradient profiles of two RO profiles that occurred at $151.50^{\circ} \mathrm{E}, 17.23^{\circ} \mathrm{N}$ on 5 October 2007 (Event 1, COSMIC, left panel) and $130.64^{\circ} \mathrm{E}, 11.18^{\circ} \mathrm{N}$ on 4 October 2020 (Event 2, COSMIC-2, right panel), which were measured between the Earth's surface and $5 \mathrm{~km}$ above it, because the ABLH usually occurs below $5 \mathrm{~km}$ [52]. The red and blue dashed lines represent the refractivity and water vapor pressure profiles, respectively ( $\mathrm{N}$ and $\mathrm{Vp}$ in Figure 3); the red and blue solid lines represent their respective gradient profiles, and the green horizontal line denotes the ABLH. The ABLHs, derived via the refractivity and water vapor pressure, are equal for both Profile 1 and Profile 2, and the ABLHs for these two RO profiles are at $0.94 \mathrm{~km}$ and $1.09 \mathrm{~km}$, respectively. It is clear that the sensitivity to the refractivity gradient is much greater than that to the water vapor pressure gradient. Therefore, the refractivity profiles from both COSMIC and COSMIC-2 were used to determine the ABLH in this study.

It can be seen from Figure 3 that sometimes there might be multiple minimum peaks in the gradient profile below $5 \mathrm{~km}, 3 \mathrm{~km}$, or even low altitudes. The minimum-gradient-based PBL definitions are the most meaningful when the profile is dominated by a single layer with large change in refractivity or moisture. For this to happen, it is necessary that the minimum gradient is large in magnitude relative to the average gradient. To quantify this condition, the relative minimum gradient or sharpness parameter is introduced as [1]:

$$
N^{\prime} \equiv-\frac{N_{\min }^{\prime}}{N_{r m s}^{\prime}}
$$

where $N_{R M S}^{\prime}$ is the root mean square (RMS) value of $N^{\prime}$ averaged over the altitude range being considered (0-5 $\mathrm{km}$ here). When $N^{\prime}$ is large, the refractivity profile sharply varies within the layer where the minimum refractivity gradient occurs. As $N^{\prime}$ decreases, the min- 
imum gradient layer becomes less distinct and finally appears virtually indistinguishable from other "layers" in the profile.
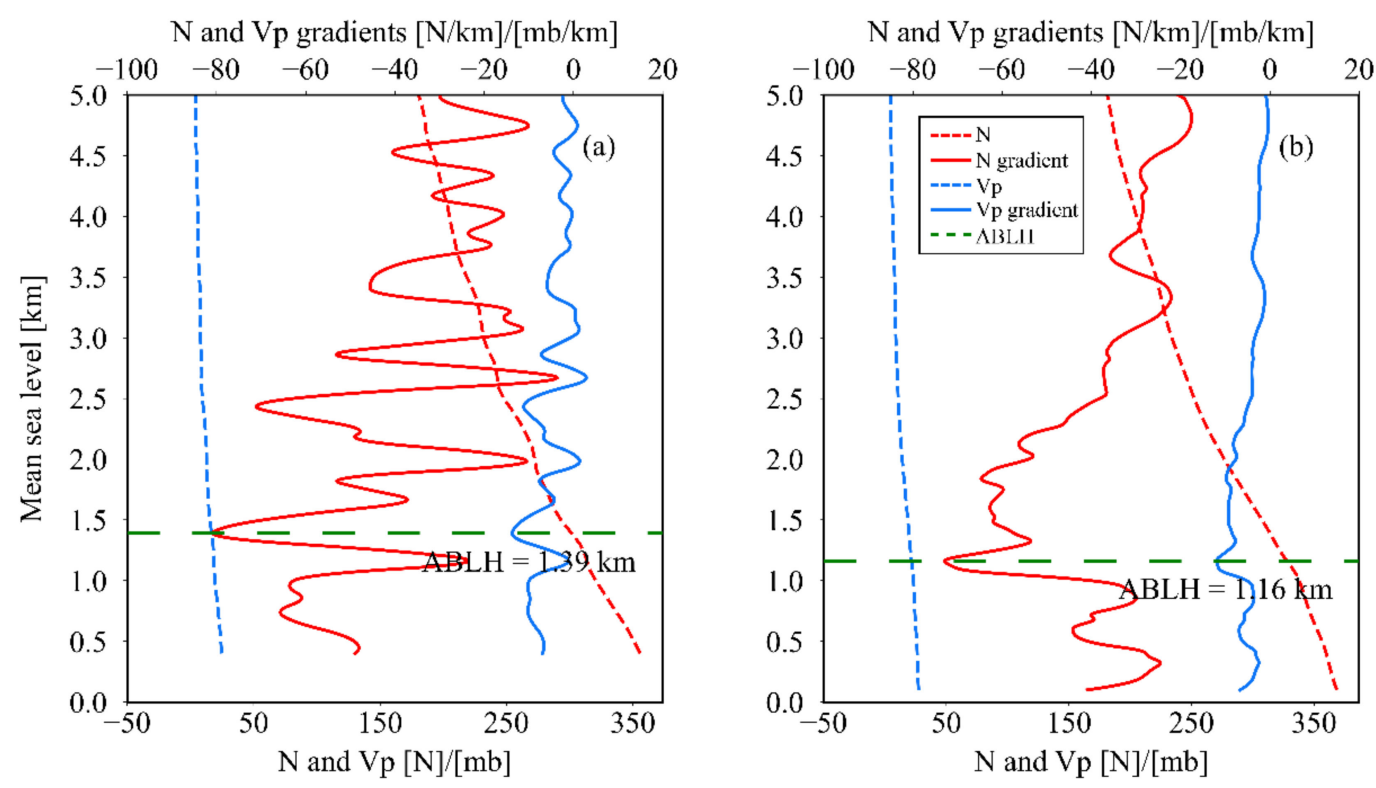

Figure 3. N, Vp, and gradient profiles for RO Profile 1 ((a) $151.50^{\circ} \mathrm{E} / 17.23^{\circ} \mathrm{N}, 5$ October 2007) and Profile $2\left((\mathbf{b}) 130.64^{\circ} \mathrm{E} / 11.18^{\circ} \mathrm{N}, 4\right.$ October 2020), as well as the results for the ABLH.

\subsection{Method for Constructing ABLH Climatology}

It is necessary to study ABLH here in order to spatio-temporally interpolate positions from several years with no typhoons in the same area, as well as to assess the difference between the ABLH during the typhoon and with the typhoon year excluded. For example, if COSMIC data are used to study the ABLH during Typhoon Usagi in 2013, the interpolation result can be obtained from the ABLH climatology from 2007-2012 and 2014-2018, without the result from 2013. Ahmad et al. showed that, as a limb-sounding technique, $\mathrm{RO}$ has a high vertical resolution but a relatively coarse along-track horizontal resolution. Although the coarse horizontal resolution will introduce some uncertainty into the ABLH estimation, previous studies have generated ABLH climatology data using the minimum refractivity gradient method, and thus verified the feasibility of this approach $[1,40]$.

In this study, a grid with a $2.5^{\circ} \times 2.5^{\circ}$ resolution was adopted in the ABLH climatology assessment using the following procedure. First, the RO profiles with "bad" quality control parameters were removed. Then, the lowest detection height of each RO profile was examined to ensure it was lower than $0.5 \mathrm{~km}$ over the ocean or $1.0 \mathrm{~km}$ over land. Finally, we co-located the $\mathrm{RO}$ profiles selected from the first two steps to each grid point and calculated the mean ABLH at each grid point. Figure 4 illustrates the proportion of the number of COSMIC (reprocess and post-process, RE and POST in Figure 4) and COSMIC-2 $\mathrm{RO}(\mathrm{C} 2$ in Figure 4) profiles with the lowest required detection height to the number of all RO profiles co-located with each grid point. In Figure 4, “_500" and "_1000" mean that the lowest detection heights are lower than $0.5 \mathrm{~km}$ and $1.0 \mathrm{~km}$, respectively (the prominent horizontal stripes in Figure 4 were caused by the projection method). It can be seen from all panels $(a-f)$ that the proportions of potentially useful RO profiles were very low over land (see the blue areas, under $20 \%$ ), which implies a much poorer performance in the detection of ABLH over land. Due to the undulating terrain of the land area, it is common that the altitude is higher than $500 \mathrm{~m}$, so the color of most of the land area is blue. In addition, although the proportions of COSMIC-2 are slightly lower than those of post-processed COSMIC, with the lowest detection heights of $<0.5 \mathrm{~km}$ and $<1.0 \mathrm{~km}$, there are still sufficient COSMIC-2 RO profiles with which to obtain more reliable ABLH climatology results, compared to COSMIC. The results for ABLH climatology will be presented in Section 3.1. Here, we need to add an explanation about why the proportions in some grids of (b) 
and (e) are larger than those of (c) and (f). First, COSMIC data from 2014 to 2018 were obtained from the post-processing method, which is different from the reprocessing method used from 2007 to 2013. Due to the poor quality of the COSMIC data from 2014 to 2018, more background information was added during post-processing, resulting in a decrease in the lowest detection height of some RO profiles, even lower than C2 data. Secondly, between 2014 and 2018, the quality and quantity of C1 data dropped sharply, resulting in more RO profiles with "bad" quality control parameters. The proportion in Figure 4 is the RO profiles whose lowest detection height is less than $500 \mathrm{~m}$ or $1000 \mathrm{~m}$ in all RO profiles whose quality control parameters are not "bad". Therefore, although the proportion is large, the actual number of RO profiles is small.
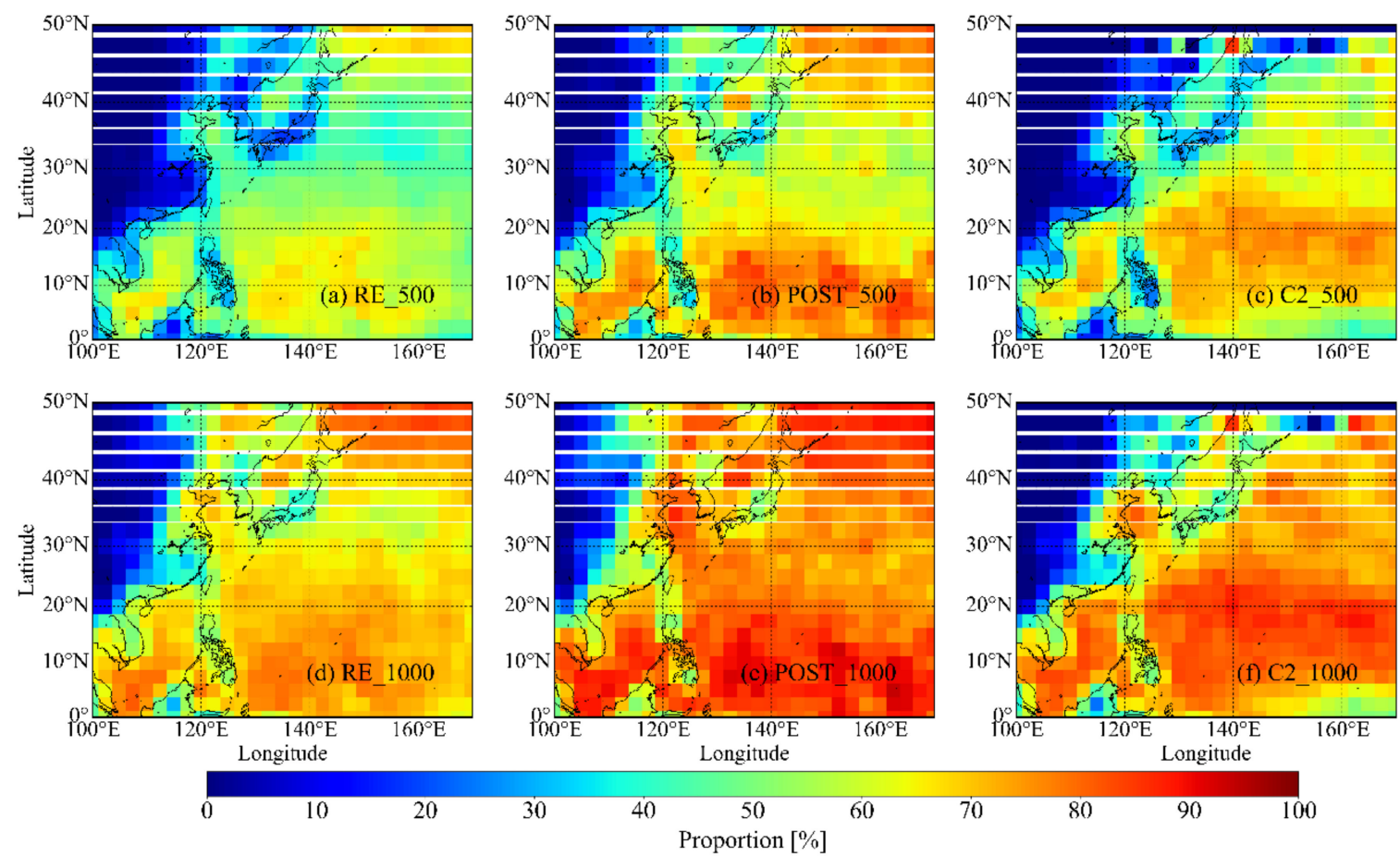

Figure 4. Proportion of reprocessed COSMIC (2007-2013, RE), post-processed COSMIC (2014-2018, POST), and COSMIC-2 profiles (2020, C2) that had the lowest detection heights below $0.5 \mathrm{~km}$ (top) and $1.0 \mathrm{~km}$ (bottom).

\subsection{Co-Location of Typhoon and RO Profiles}

The key to using RO data to study the ABLH during a typhoon period is the identification or determination of the RO profiles that are co-located with the track of the typhoon. For example, Figure 5 shows the tracks of typhoons TY5 (a) and TY12 (b) as well as their co-located RO profiles, where the dots denote the positions of the typhoons' centers and the colors of the dots denote wind speed (in $\mathrm{m} / \mathrm{s}$ ). The big circles (with a $600 \mathrm{~km}$ radius) define the co-location range of $\mathrm{RO}$ profiles with the typhoon center in the spatial domain, and the red stars (within the big circles) represent the RO profiles co-located within a $36 \mathrm{~h}$ time window in (a) and a $12 \mathrm{~h}$ time window in (b). Figure 5 indicates that the number of co-located COSMIC-2 profiles is much greater than that of COSMIC profiles; in fact, each typhoon's central position has at least one co-located COSMIC-2 profile with a $6 \mathrm{~h}$ time window. Therefore, the result obtained from COSMIC-2 will be more reliable.

For COSMIC, to address the fact that the determination of the ABLH is limited by the lowest detection height of the $\mathrm{RO}$ profiles within a $600 \mathrm{~km}$ radius, the time windows for co-location were enlarged. Various time windows, including $6 \mathrm{~h}, 12 \mathrm{~h}, 18 \mathrm{~h}, 24 \mathrm{~h}, 30 \mathrm{~h}$, and $36 \mathrm{~h}$ before and after the typhoons' central positions, were tested in order to compare the variation trends of the ABLHs, as determined from their corresponding co-located RO profiles. The test results show that the ABLHs within a $12 \mathrm{~h}$ time window during all nine typhoons had similar variation trends, and the $36 \mathrm{~h}$ time window was the shortest that 
resulted in continuous variation in the ABLH along the typhoons' track. For COSMIC-2, there is no problem of insufficient data, and its results, based on a $12 \mathrm{~h}$ time window, will be shown in Section 3.2.
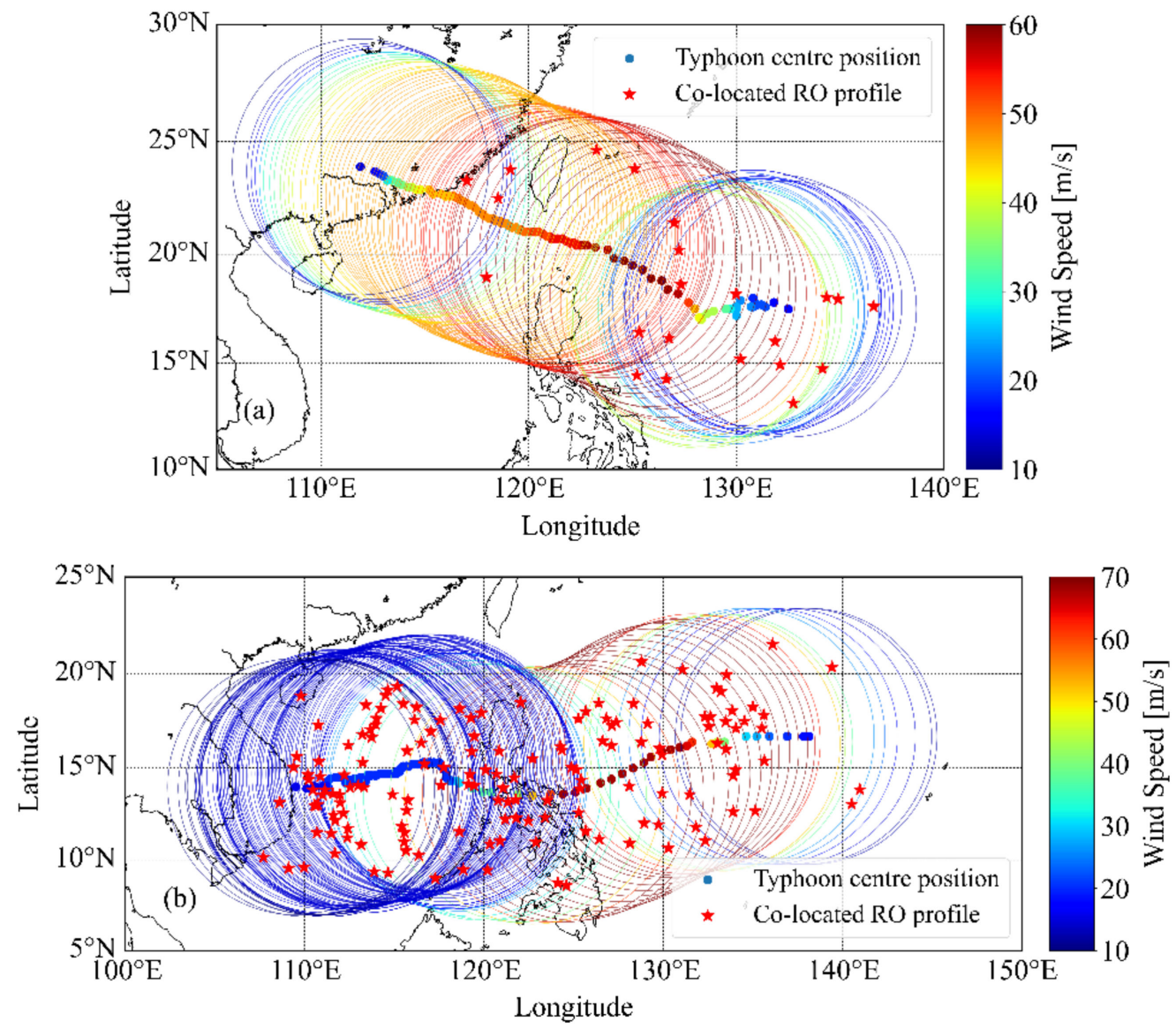

Figure 5. Examples of the co-location of typhoons and RO profiles (red stars) based on a $600 \mathrm{~km}$ radius. The time windows are $36 \mathrm{~h}$ and $12 \mathrm{~h}$ in (a) Usagi (TY5) with COSMIC and in (b) Goni (TY12) with COSMIC-2. Colors indicate the wind speed in $\mathrm{m} / \mathrm{s}$.

When more than one co-located RO profile is found for the same typhoon central position (see Figure 5), the weights of each of the co-located RO profiles need to be determined. The following Gaussian weighting functions with the variables of time and distance were used in this study [53]:

$$
w_{i}=\exp \left(-\left[\left(\frac{\Delta d}{D}\right)^{2}+\left(\frac{\Delta t}{T}\right)^{2}\right]\right)
$$

where $i$ is the index of the co-located RO profile; $w_{i}$ is the weight of the $i$ th RO profile; $D$ and $T$ are the ranges or sizes defined for the space and time windows, respectively; and $\Delta d$ and $\Delta t$ are the spatial distance and the time difference between the $i t h$ RO profile and the typhoon center, respectively.

\section{Analysis Results}

\subsection{ABLH Climatology in Typhoon Season}

Figure 6 shows the ABLH climatology during the local typhoon season (July-October) obtained from $\mathrm{RO}$ refractivity data on a $2.5^{\circ} \times 2.5^{\circ}$ grid. $(\mathrm{a}-\mathrm{c})$ are the results of reprocessed COSMIC (2007-2013), post-processed COSMIC (2014-2018), and COSMIC-2 (2020) data, respectively; note that the mean ABLH of each grid is the mean of the results at four adjacent points. The means of all ABLHs in $(\mathrm{a}-\mathrm{c})$ were $1.54 \mathrm{~km}, 1.58 \mathrm{~km}$, and $1.15 \mathrm{~km}$, 
and the result obtained from COSMIC-2 was about $0.4 \mathrm{~km}$ smaller than that from COSMIC. $(\mathrm{a}-\mathrm{c})$ all indicate that the ABLH over the ocean was lower than that over land and that it was relatively more stable. The reason for this decrease was that a higher SNR improved the ability of COSMIC-2 to detect refractivity and other parameters at lower altitudes; therefore, many RO profiles with ABLHs below $0.5 \mathrm{~km}$ were added into the calculation of ABLH climatology. This reduction also confirmed the point raised in the study by Ao et al. that COSMIC's data are not very well-suited to inferring the depths of shallower ABLs [1].

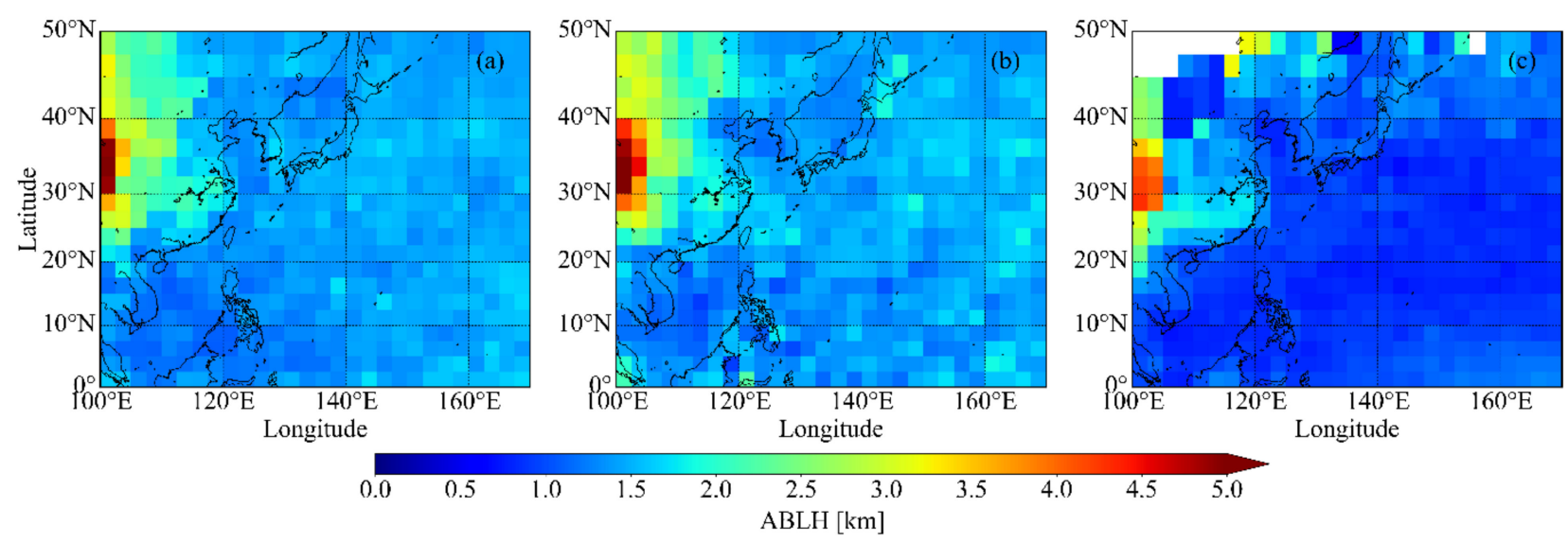

Figure 6. ABLH climatology during the local typhoon season (July-October). (a,b) are the results of reprocessed and post-processed COSMIC data, and (c) is the result of COSMIC-2 data.

\subsection{Co-Location Results Based on Various Time Windows}

As mentioned in Section 2.5, with the consideration of limited COSMIC profiles, we have extended the time co-location window on the basis of previous studies and tested six windows. Note that we only discuss the co-location results of COSMIC in this section because the COSMIC-2 profiles were sufficient in terms of quantity and quality, and a $6 \mathrm{~h}$ time window was used in this study. Some studies have proven that a $6 \mathrm{~h}$ window was suitable for the study of the variation characteristics of atmospheric parameters, such as temperature, humidly, and the tropopause height, and even those co-located RO profiles with lowest detection heights above the ABLH can be used. However, the number of colocated $\mathrm{RO}$ profiles, determined based on this window size, used for obtaining the ABLH in the region of study is very low; about half of the RO profiles cannot be used for ABLH calculation, according to Figure 4 . As a result, instead of using the $6 \mathrm{~h}$ window, the $12 \mathrm{~h}$ window was adopted for the definition of the co-location range, so as to ensure sufficient quantities of co-located RO profiles. Table 3 compares the numbers of co-located RO profiles based on different time windows for each of the nine typhoons. "Num" denotes the number of co-located RO profiles, and the "\%" column denotes the proportion of typhoon central positions that had at least one co-located RO profile among all the typhoons' central positions. Table 3 shows that most of the proportion results in the $12 \mathrm{~h}$ column were above $60 \%$, and those in the $36 \mathrm{~h}$ column were above 95\%. For COSMIC, the $12 \mathrm{~h}$ time window was used to investigate the mean ABLH in each of the nine typhoons, and the $36 \mathrm{~h}$ time window was used to analyze the continuous variation in the ABLH along the tracks of the nine typhoons.

For COSMIC-2, almost all the central positions of the three typhoons in 2020 were co-located with more than one RO profile based on the $12 \mathrm{~h}$ time window. When TY11 moved into a latitude higher than $45^{\circ}$ there were no co-located RO profiles because the COSMIC profiles were located within $\pm 45^{\circ}$ latitudes. 
Table 3. Number of COSMIC profiles that were co-located with each of the nine typhoon tracks (in Table 2) in various time windows ("Num" denotes the number of co-located COSMIC profiles; "\%" denotes the proportion of typhoon central positions that had at least one co-located RO profile amongst all the typhoons' central positions).

\begin{tabular}{|c|c|c|c|c|c|c|c|c|c|c|c|c|}
\hline \multirow{3}{*}{ Typhoon } & \multicolumn{12}{|c|}{ Time Window } \\
\hline & \multicolumn{2}{|c|}{$6 \mathrm{~h}$} & \multicolumn{2}{|c|}{$12 \mathrm{~h}$} & \multicolumn{2}{|c|}{$18 \mathrm{~h}$} & \multicolumn{2}{|c|}{$24 \mathrm{~h}$} & \multicolumn{2}{|c|}{$30 \mathrm{~h}$} & \multicolumn{2}{|c|}{$36 \mathrm{~h}$} \\
\hline & Num & $\%$ & Num & $\%$ & Num & $\%$ & Num & $\%$ & Num & $\%$ & Num & $\%$ \\
\hline TY1 & 12 & 42 & 15 & 56 & 18 & 67 & 22 & 78 & 27 & 86 & 30 & 89 \\
\hline TY2 & 28 & 57 & 26 & 80 & 41 & 91 & 44 & 98 & 49 & 100 & 53 & 100 \\
\hline TY3 & 10 & 45 & 10 & 63 & 11 & 77 & 12 & 88 & 17 & 95 & 19 & 100 \\
\hline TY4 & 9 & 44 & 11 & 67 & 12 & 86 & 17 & 98 & 19 & 100 & 21 & 100 \\
\hline TY5 & 14 & 54 & 16 & 76 & 16 & 82 & 19 & 89 & 21 & 99 & 22 & 100 \\
\hline TY6 & 4 & 21 & 8 & 50 & 10 & 63 & 13 & 75 & 18 & 92 & 21 & 96 \\
\hline TY7 & 14 & 59 & 19 & 71 & 22 & 89 & 26 & 100 & 31 & 100 & 35 & 100 \\
\hline TY8 & 20 & 54 & 26 & 70 & 30 & 79 & 33 & 87 & 38 & 94 & 42 & 96 \\
\hline TY9 & 4 & 15 & 5 & 26 & 7 & 38 & 8 & 48 & 9 & 62 & 12 & 76 \\
\hline Average \% & & 43 & & 62 & & 75 & & 85 & & 92 & & 95 \\
\hline
\end{tabular}

\subsection{Mean ABLH in Typhoons}

Table 1 indicates the six stages of typhoons classified by the CMA. In this section, the first three stages (TD, TS, and STS) were merged into T1 and the last three stages (TY, STY, and super TY) were merged into T2 to give a preliminary result of the temporal variations in the ABLHs of $\mathrm{T} 1$ and $\mathrm{T} 2$ in the twelve typhoons. Table 4 shows the results based on a $12 \mathrm{~h}$ time window. The values in the Mean1 and Mean 2 columns denote the mean ABLHs of TY1-TY9 and TY10-TY12, respectively, and the value in the T1-T2 row is the difference between the results of the T1 and T2 rows. Among the values of TY1-TY9 in the T1-T2 rows, the minimum was $0.18 \mathrm{~km}$, derived from TY7, while the maximum was $1.63 \mathrm{~km}$, derived from TY9. This results from the fact that TY9 occurred in 2016, during which the COSMIC mission approached completion, and thus the amount of RO data was limited. For COSMIC-2, the ABLH during TY10-TY12 also showed the same characteristics as TY1-TY9. All the positive values in the T1-T2 row in Table 4 indicate that the ABLH at $\mathrm{T} 1$ was larger than that at $\mathrm{T} 2$, and the $\mathrm{ABLH}$ at $\mathrm{T} 2$ was, on average, $0.72 \mathrm{~km}$ and $0.38 \mathrm{~km}$ lower than the ABLH at T1, based on COSMIC and COSMIC-2, respectively.

Table 4. ABLH (km) of T1 (mean of TD, TS and STS) and T2 (mean of TY, STY, and super TY) of each typhoon resulting from the co-located $\mathrm{RO}$ profiles within the $12 \mathrm{~h}$ time window.

\begin{tabular}{ccccccccccccccc}
\hline RO & \multicolumn{1}{c}{ COSMIC } & \multicolumn{1}{c}{ COSMIC-2 } \\
\hline TY & TY1 & TY2 & TY3 & TY4 & TY5 & TY6 & TY7 & TY8 & TY9 & Mean1 & TY10 & TY11 & TY12 & Mean2 \\
\hline T1 & 2.02 & 1.18 & 2.07 & 2.51 & 1.44 & 1.50 & 0.89 & 1.70 & 2.10 & 1.71 & 0.87 & 1.09 & 0.87 & 0.94 \\
T2 & 0.97 & 0.88 & 1.01 & 1.75 & 0.86 & 1.20 & 0.71 & 1.11 & 0.47 & 0.99 & 0.59 & 0.64 & 0.46 & 0.56 \\
T1-T2 & 1.05 & 0.31 & 1.07 & 0.76 & 0.58 & 0.30 & 0.18 & 0.59 & 1.63 & 0.72 & 0.28 & 0.45 & 0.41 & 0.38 \\
\hline
\end{tabular}

\subsection{Variation in ABLH along Typhoon Track}

In Section 3.3, a $12 \mathrm{~h}$ time window was used to study the mean ABLH during the twelve typhoons. However, for TY1-TY9, nearly $40 \%$ of the typhoons' central positions were colocated with no RO profiles, making it difficult to obtain continuous ABLH data along the typhoons' tracks for investigating the characteristics of the variation in the ABLH. To address this issue, in this section a $36 \mathrm{~h}$ time window was adopted, which ensures that more than $95 \%$ of the typhoons' central positions have at least one co-located RO profile. In fact, a $36 \mathrm{~h}$ window size is not ideal for studying the typhoons' tracks. However, the amount of COSMIC RO data used in this study is fixed, and even if a typhoon's central position is distant from the current typhoon central position within the $36 \mathrm{~h}$ window, the ABLH over both positions generally varies slowly in the temporal domain. For COSMIC-2, there is no 
need to consider the lack of data, because each typhoon central position can co-locate with at least one RO profile, except those located at latitudes higher than $45^{\circ}$. Therefore, if more than one co-located RO profile exists for a given typhoon, it is common to use different weights for different co-located RO profiles when calculating the mean ABLH for each typhoon central position; in this study, the Gaussian weighting function was used to determine the weight.

The results for TY1-TY9 are shown in Figure 7, where each panel (except for the last one) indicates the continuous variation in the ABLH along the track of the typhoon, derived from the RO profiles spatially and temporally co-located with the typhoon's central position (within a $36 \mathrm{~h}$ time window and a $600 \mathrm{~km}$ radius, red curve) and the results from ABLH climatology (green curve). The red and green horizontal dashed lines represent the mean ABLH for the whole duration of the typhoon obtained from co-located RO profiles and the climatology. The purple, orange, and blue vertical dashed lines denote the start and end of the super TY (which is also contained in T2), T2, and T1 stages, respectively. The time shown in the abscissa is UTC +8 , and the spacing of the abscissas varies due to the uneven time intervals of the typhoons' central positions. It should be noted that there are unusual high ABLHs $(>3 \mathrm{~km}$ ) during the T1 stage in several cases, which is due to the fact that some typhoon path points had only one co-located RO profile, and the ABLH calculated by this $\mathrm{RO}$ profile is lower than $5 \mathrm{~km}$, which is lower than the maximum value of ABLH we set, so we kept these unusual high ABLHs.
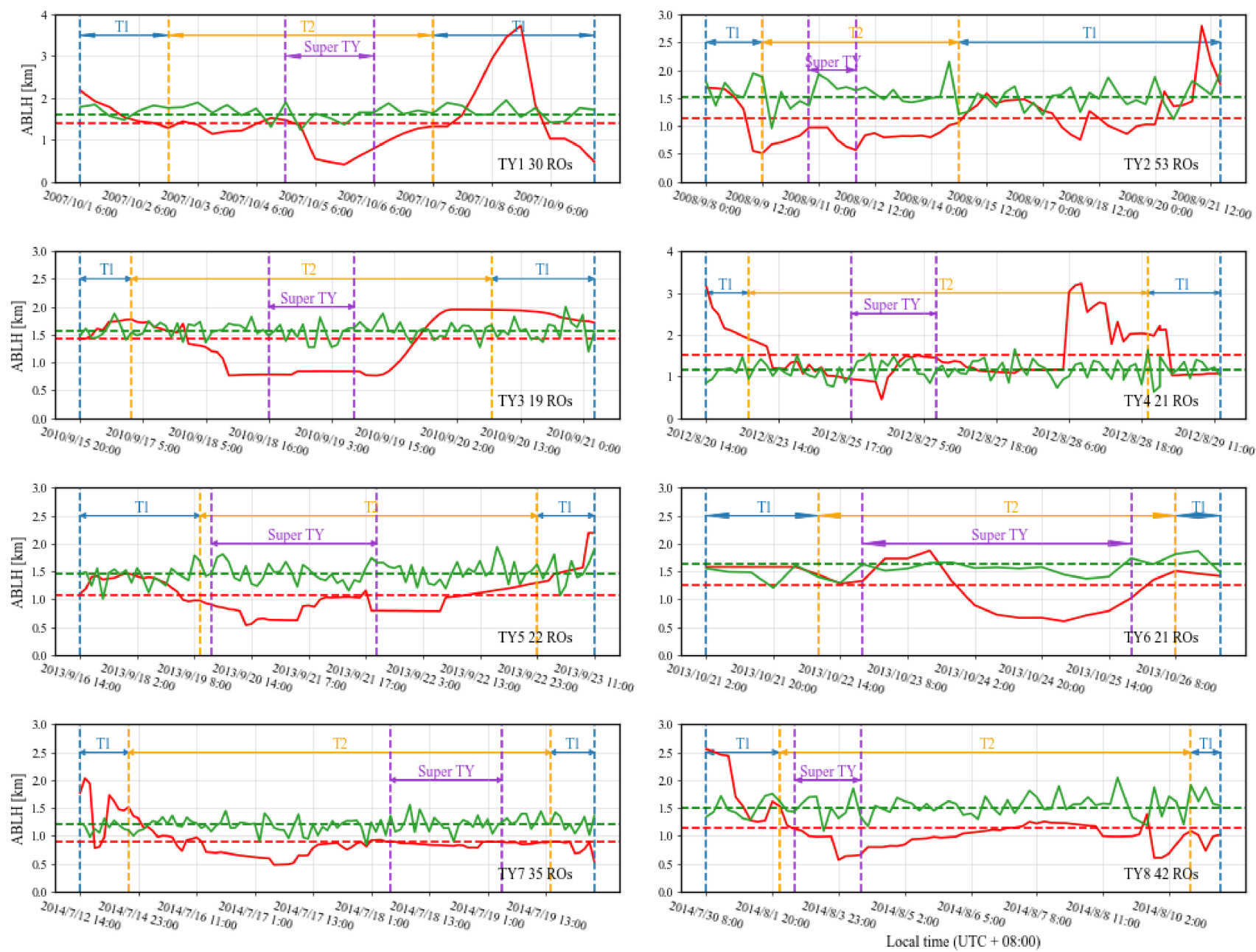

Figure 7. Cont. 

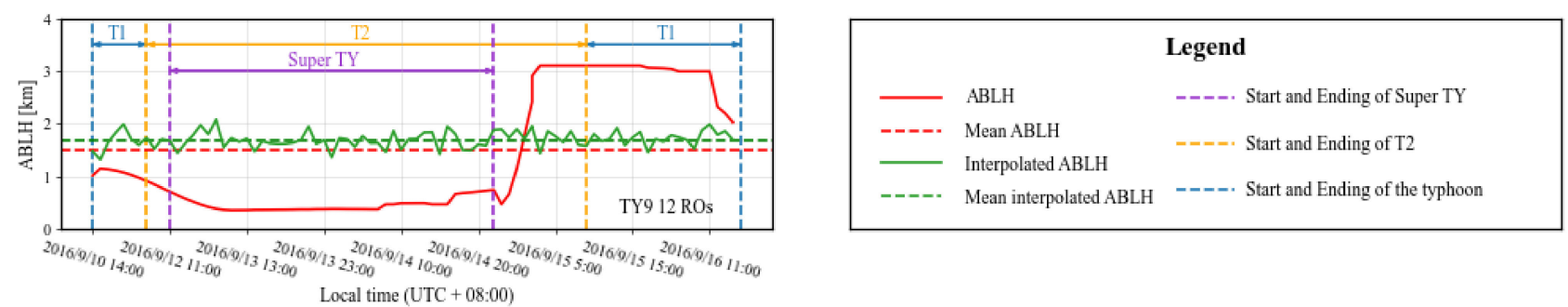

Figure 7. Variation in the ABLH along each typhoon's (TY1-TY9) track, resulting from the co-located COSMIC profiles (based on a $600 \mathrm{~km}$ space window and a $36 \mathrm{~h}$ time window, red curve) and the results from ABLH climatology (green curve). The red and green horizontal dashed lines are the mean ABLH during the typhoon period obtained from the co-located RO profiles and the climatology. The stages of T1, T2, and super TY are represented by the blue, orange, and purple vertical dashed lines, respectively.

In each panel of Figure 7, comparing the ABLH between T1 and T2, one can find that, except for TY7, all results at T1 were greater than at T2, and the ABLH had a downward trend with an increase in wind speed (see the part before the start point of super TY). Moreover, except for TY2, TY3, and TY7, the ABLHs of all the other typhoons reached their minimums at the super TY stage, while the ABLH of TY2, TY3, and TY7 reached their minimums at the T2 stage. Moreover, the curves in none of the panels are smooth, and the reasons are as follows: Firstly, COSMIC provided more than $1500 \mathrm{RO}$ profiles daily over the globe in the period from 2007 to 2013, but after this period, the available RO profiles gradually decreased due to the degradation of COSMIC satellites. For example, the number of co-located COSMIC profiles for TY9 in 2016 was small, since this year was close to the end of the COSMIC mission. Second, the number of typhoon central positions on record was also small (e.g., 31 positions of TY1 and 25 positions of TY6). Generally, the shorter the duration of a typhoon, the smaller the number of its co-located RO profiles.

The results for TY10-TY12 are shown in Figure 8, which is based on COSMIC-2 profiles in a $12 \mathrm{~h}$ time window, and the legend of Figure 8 is the same as that of Figure 7. The ABLHs during the three typhoons have similar characteristics, including the fact that (1) the ABLH gradually decreased during the first T1 stage, (2) the ABLH maintained a low altitude during the T2 stage, which reached a minimum at the super TY stage, and (3) the ABLH gradually rose during the second T1 stage. Note that for the last part of TY10, no COSMIC-2 profile is available, because the track of TY10 moved into an area with a latitude of more than $45^{\circ}$.

Table 5 shows the mean ABLH during each typhoon (TY_YEAR row) and the mean ABLHs obtained from the ABLH climatology devised in Section 3.1 (NO_TY row), which means that the ABLH in the year of the typhoon was excluded. The difference between the TY_YEAR row and the NO_TY row of each typhoon is shown in the DIF row. Table 5, based on a $600 \mathrm{~km}$ spatial window and a $36 \mathrm{~h}$ time window, shows the co-located COSMIC profiles, while the time window was $12 \mathrm{~h}$ for the COSMIC-2 profiles. As regards the mean ABLH values in the TY_YEAR and NO_TY rows, the former was smaller than the latter, except for TY4. The difference between the results of the rows may be partly due to the exclusion of the one year of data during the typhoon. All the negative values in the DIF row, except for TY4, indicate that the mean ABLH decreased compared with its counterparts, resulting from the exclusion of the year of the typhoon.

Table 5. Mean ABLH (in km) of each typhoon in Figures 7 and 8 (TY_YEAR row) and the mean ABLH over the region of each typhoon derived from the ABLH climatology (the ABLH in the year of the typhoon was excluded; NO_TY row). The DIF row shows the difference between TY_YEAR and NO_TY.

\begin{tabular}{ccccccccccccc}
\hline TY & TY1 & TY2 & TY3 & TY4 & TY5 & TY6 & TY7 & TY8 & TY9 & TY10 & TY11 & TY12 \\
\hline TY_YEAR & 1.40 & 1.13 & 1.44 & 1.53 & 1.08 & 1.26 & 0.89 & 1.14 & 1.49 & 0.67 & 0.78 & 0.79 \\
NO_TY & 1.59 & 1.52 & 1.57 & 1.17 & 1.45 & 1.63 & 1.21 & 1.51 & 1.69 & 0.95 & 0.92 & 1.01 \\
DIF & -0.19 & -0.39 & -0.13 & 0.36 & -0.37 & -0.37 & -0.32 & -0.37 & -0.20 & -0.28 & -0.14 & -0.22 \\
\hline
\end{tabular}



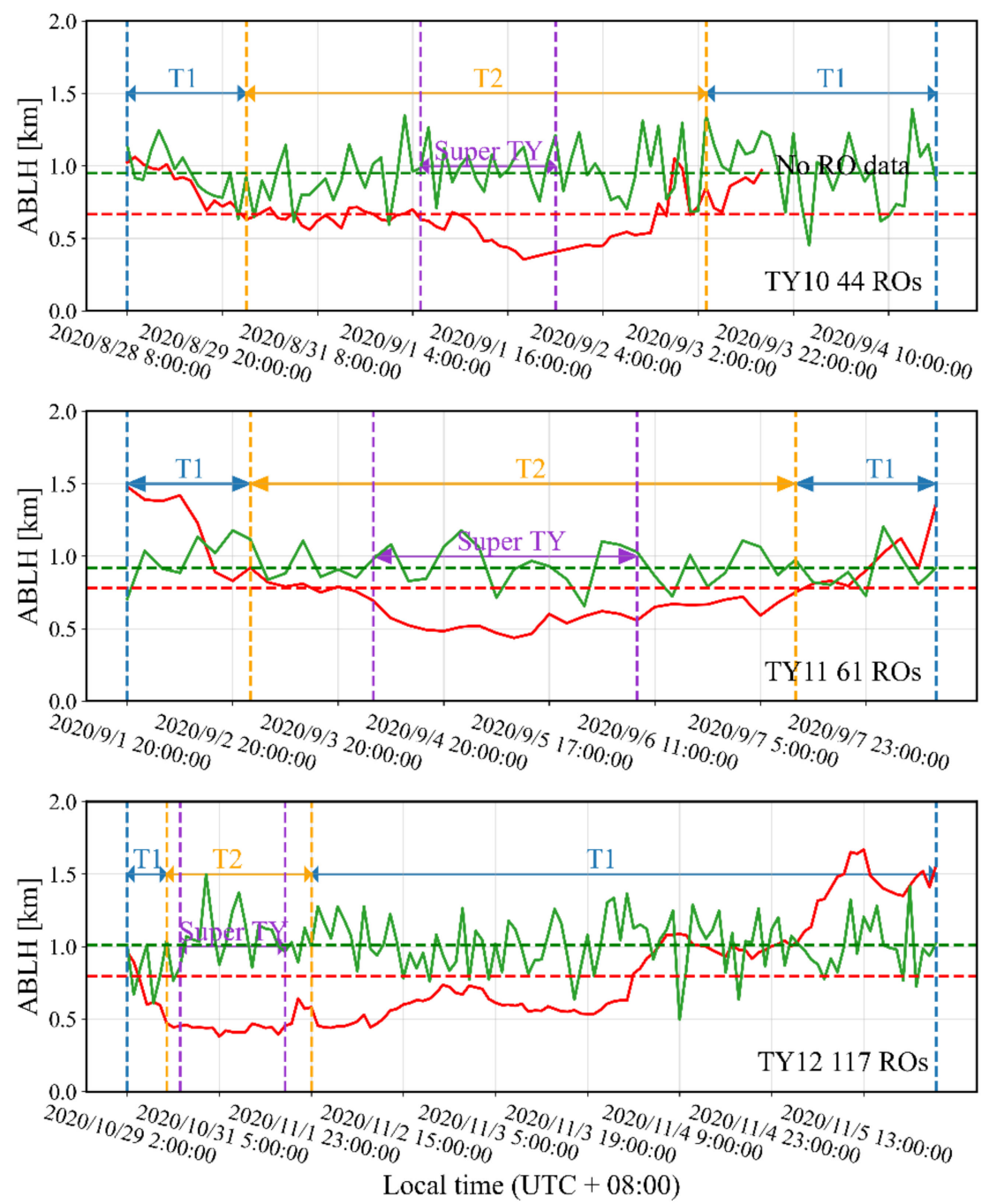

Figure 8. Variation in the ABLH along each typhoon's (TY10-TY12) track, resulting from the colocated COSMIC-2 profiles (based on a $600 \mathrm{~km}$ spatial window and a $12 \mathrm{~h}$ time window, red curve) and the results from ABLH climatology (green curve). The legend of Figure 8 is the same as the legend of Figure 7.

\subsection{Mean ABLH at Different Stages of Typhoons}

All the mean ABLHs discussed in previous sections are the results at the T1 and T2 stages, assessed for a preliminary investigation of the variation trend of the ABLH. In this section, the mean ABLHs at the six stages of each typhoon (also based on a $600 \mathrm{~km}$ spatial window and a $36 \mathrm{~h}$ time window for COSMIC, and a $12 \mathrm{~h}$ time window for COSMIC-2) are compared, as shown in Figure 9. Some missing data for TY6 and TY8 are the cause of the null bars in the figure. It can be seen that the mean ABLHs were higher at the stages of TD, TS, and STS than that at the stages of TY, STY, and super TY, which is consistent with T1 being larger than T2, as stated in Section 3.3. The ABLHs almost reached their maximum at the TD stage, while they reached their minimum at either the STY stage or the super TY stage. However, the variations in the mean ABLHs at TY3 and TY7 were abnormal, i.e., the ABLH values were low at the stages of TD and TS, but the values decreased with an increase in wind speed from the STS stage to the super TY stage, due to the recording of only six and one positions in the TD stage during TY3 and TY7, respectively. As such, their co-located RO profiles were of limited utility for obtaining a reliable result. For TY10-TY12, the mean ABLH also gradually decreased from TD to super TY, and the ABLH at the TY stage was slightly higher than that at the SYS stage during TY12 only. 


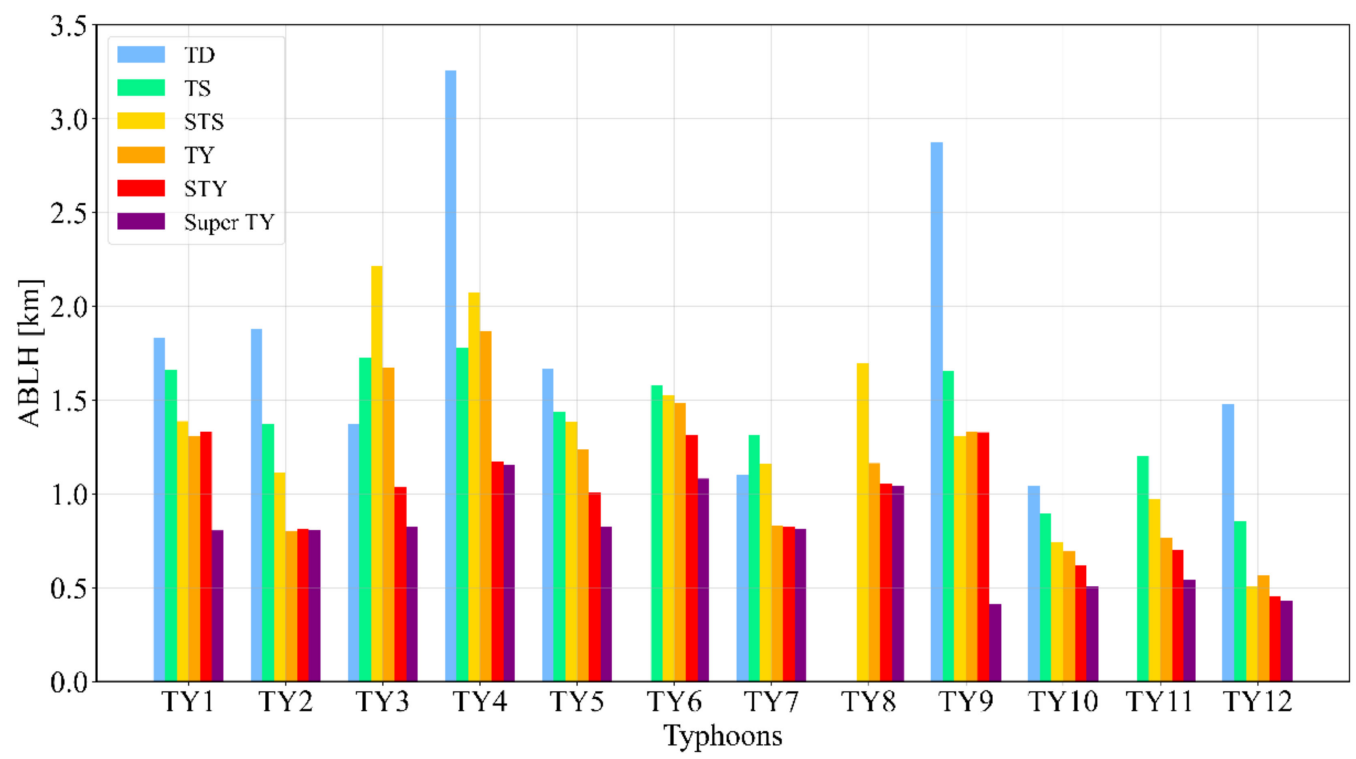

Figure 9. Comparison of the mean ABLHs between different stages of each typhoon. Different colors represent the six stages, defined by the CMA, according to wind speed.

In this section, it is plain that the ABLHs at the six stages of the twelve typhoons roughly display the same characteristic, that is, the ABLH decreased as the typhoon's intensity increased. Moreover, the minimum ABLH during most typhoons appeared at the super TY stage, when the typhoon intensity was at its highest, although the minimum ABLH during TY2 was reached at the STY stage, which is close to the super TY stage.

\subsection{Correlation Analysis between the ABLH and Wind Speed}

Typhoons have an influence on the ABLH, and this influence is related to the typhoon's intensity, which is defined by wind speed. To discuss this influence, we studied the influence of the relationship between the ABLH and wind speed on each typhoon's central position, and calculated the correlation coefficients between the ABLH and wind speed during the twelve typhoons. The results are shown in Figure 10. The correlation coefficient between the ABLH and wind speed of each typhoon is represented by $r$ and marked in each subplot. Note that the maximum ABLH was $4.0 \mathrm{~km}$ and $2.0 \mathrm{~km}$ for a-i and $\mathrm{j}-1$, respectively. The correlation coefficients of (e) Usagi, (i) Meranti, and (k) Haishen are higher than 0.8, which suggests that the ABLH is strongly correlated with wind speed. The correlation coefficients of (b) Sinlaku, (c) Fanapi, (f) Lekima, (h) Halong, (j) Maysak, and (l) Goni are in the range of moderate correlation, while the correlation coefficients of other typhoons are in the range of low correlation, except for (g) Rammasun. The mean correlation coefficient of the twelve typhoons in this study is -0.607 , which shows that the ABLH and typhoon wind speed are moderately correlated. There are two mechanisms that explain typhoons (i) Meranti and (1) Goni: (1) At the end of Meranti, many central positions on the typhoon's track were co-located with the same RO profile, which resulted in different wind speeds corresponding to the same ABLH. (2) In the second T1 stage of Goni, there were more than 30 central positions at which the wind speed was $20 \mathrm{~m} / \mathrm{s}$. These explain the abnormalities of Figure 10i,l. 

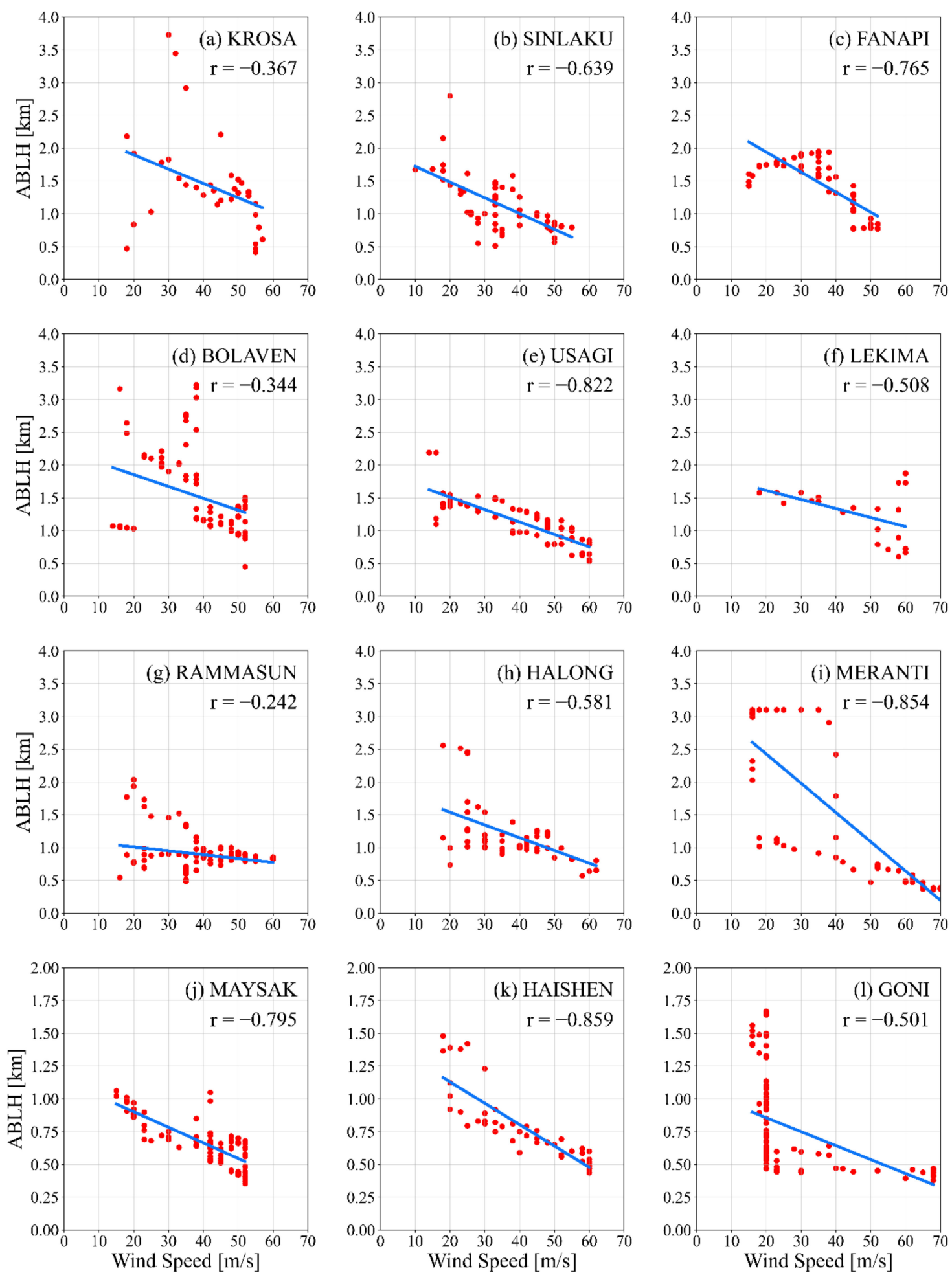

Figure 10. The relationship between the ABLH and wind speed during typhoons in this study. The correlation coefficient between the ABLH and wind speed of each typhoon is represented by $r$ and marked in each subfigure. (a-1) represent the results of each typhoon arranged in the order of twelve typhoons.

\section{Discussion and Conclusions}

In this study, the refractivity profiles derived from COSMIC (2007-2018) and COSMIC2 (2020) datasets during typhoon season over the Northwest Pacific were used to investigate the influence of a typhoon on the ABLH. The algorithm used to determine the ABLH was the minimum gradient of refractivity of the RO profiles that were co-located with the 
position of the typhoon track. The co-located RO profiles were based on a $600 \mathrm{~km}$ spatial window and various time windows, and when there was more than one RO profile colocated with a typhoon's central position the weight of each co-located RO profile was determined by the Gaussian weighting function. To compare the ABLH in the year the selected typhoon occurred and the mean ABLH in the same period and at the same position, but excluding the year the typhoon occurred, the ABLH climatology (with a $2.5^{\circ} \times 2.5^{\circ}$ horizontal resolution) over the Northwest Pacific was assessed based on RO data during the summer typhoon season. Given that the lowest effective detection height of about $50 \%$ of COSMIC's RO profiles was above $0.5 \mathrm{~km}$, a $12 \mathrm{~h}$ time window was adopted for testing the mean ABLH during typhoons. For COSMIC, to ensure that more than $95 \%$ of the typhoon central positions had more than one co-located RO profile, and based on the test results of various lengths of time windows, a $36 \mathrm{~h}$ time window was adopted in the investigation of the ABLH along the typhoon track. For COSMIC-2, because it provided sufficient RO profiles over tropical and subtropical areas, and because each typhoon's central position was co-located with at least one RO profile within a $12 \mathrm{~h}$ time window, the $12 \mathrm{~h}$ time window was adopted in the co-location of typhoon centers and COSMIC-2 profiles.

The results based on a $12 \mathrm{~h}$ time window show that the mean ABLHs in the T1 stage were larger than the ABLHs in the T2 stage, based on both COSMIC and COSMIC-2 data. The $36 \mathrm{~h}$ and $12 \mathrm{~h}$ time windows were used for COSMIC and COSMIC-2 to study the continuous variation in the ABLH along the typhoon's track. The minimum ABLH of most typhoons appeared in the super TY stage. We also used ABLH climatology to obtain the ABLH at the same position when there was no typhoon, and compared it with the ABLH when the typhoon occurred. The ABLHs obtained from the co-located RO profiles in a typhoon's track were $0.13-0.39 \mathrm{~km}$ lower than the interpolated ABLHs derived from the climatology assessment, except for Bolaven. The ABLH was significantly reduced during the selected typhoon compared to the ABLH measured without a typhoon. The correlation coefficient between the ABLH and wind speed of each typhoon was also studied. The mean correlation coefficient of the twelve typhoons was -0.607 , which indicates that the ABLH and typhoon wind speed are moderately correlated-as wind speed increased, the ABLH gradually decreased.

This study focuses more on the numerical characteristics of and variation within the ABLH during typhoons, based on RO data. The physical explanation of why the ABLH decreased during some typhoons involves complicated knowledge of atmospheric physics, and a more detailed physical explanation will be carried out in further work. Here, we give our conjecture about the possible reason. The gradient reflects the magnitude of the data change. Typhoons are usually accompanied by heavy rainfall, which causes water vapor to move to the surface and dramatic changes in the vertical direction of the water vapor, resulting in a decrease in the minimum altitude of the water vapor partial pressure gradient. According to our formula and previous studies, the refractivity gradient will also be affected - the minimum height of the refractivity gradient will be reduced, eventually causing a reduction in the ABLH.

The water vapor pressure of $\mathrm{RO}$ was also used to study the ABLH in some studies; however, given that the water vapor pressure of RO depends on refractivity, as well as a first-guess background and the 1D-Var retrieval process, we only used the refractivity profile in this study. Although the results for the water vapor pressure are not as reliable as those for refractivity, we also used the water vapor pressure profile in our experiment, and the conclusion based on water vapor pressure is similar to that based on refractivity.

Based on twelve typhoons, we proposed a mesoscale negative correlation between the ABLH and wind speed during typhoons, and we enlarged the time window of co-location to obtain the ABLH along the typhoons' tracks. The number of typhoon samples used in this study was somewhat low, but all were selected according to the selection criteria designed in Section 2.2. Moreover, although the time window was enlarged in order to enable the use of more co-located RO profiles to investigate the mean ABLH along the typhoon track, the co-located COSMIC profiles were still limited. This study is limited 
by the small number of typhoons and the small number of $\mathrm{RO}$ observations prior to the launch of COSMIC-2. COSMIC-2 provides many more RO profiles in the tropics than COSMIC, and the higher SNR of COSMIC-2 allows for significantly more RO profiles that penetrate low into the ABL, as noted by Schreiner et al. [35]. In future research we will use the large number of high-SNR COSMIC-2 profiles in the tropics, as well as other RO missions, to confirm and extend these results.

Author Contributions: Conceptualization, J.S. and K.Z.; methodology, J.S.; validation, Z.S.; formal analysis, J.S. and S.S.; writing-original draft preparation, J.S.; writing-review and editing, S.W. and K.Z.; visualization, J.S.; supervision, S.W. and K.Z.; project administration, K.Z.; funding acquisition, K.Z. All authors have read and agreed to the published version of the manuscript.

Funding: This research was funded by the State Key Program of National Natural Science Foundation of China (grant No. 41730109), the National Natural Science Foundation of China (grant No. 41874040), the Jiangsu Dual Creative Talents and Jiangsu Dual Creative Teams Programme Projects awarded in 2017, and the Postgraduate Research \& Practice Innovation Program of Jiangsu Province (grant KYCX21_2302).

Institutional Review Board Statement: Not applicable.

Informed Consent Statement: Not applicable.

Data Availability Statement: Publicly available datasets were analyzed in this study. The COSMIC and COSMIC-2 RO data were obtained from CDAAC (https:/ / www.cosmic.ucar.edu/ (accessed on 20 September 2020)) and the typhoon track website of the Zhejiang Water Provincial Resources Department (http:/ / typhoon.zjwater.gov.cn/ (accessed on 15 October 2020)).

Acknowledgments: We acknowledge CDAAC for the use of the COSMIC and COSMIC-2 RO datasets. We are also thankful for the typhoon tracks data provided by the Zhejiang Water Provincial Resources Department.

Conflicts of Interest: The authors declare no conflict of interest.

\section{References}

1. Ao, C.O.; Waliser, D.E.; Chan, S.K.; Li, J.-L.; Tian, B.; Xie, F.; Mannucci, A.J. Planetary boundary layer heights from GPS radio occultation refractivity and humidity profiles. J. Geophys. Res. Atmos. 2012, 117, D16117. [CrossRef]

2. Emanuel, K. An Air-Sea Interaction Theory for Tropical Cyclones. Part I: Steady-State Maintenance. J. Atmos. Sci. 1986, 43, 585-605. [CrossRef]

3. Wroe, D.; Barnes, G. Inflow Layer Energetics of Hurricane Bonnie (1998) near Landfall. Mon. Weather Rev. 2003, 131, 1600-1612. [CrossRef]

4. Smith, R.; Montgomery, M.; Vogl, S. A critique of Emanuel's hurricane model and potential intensity theory. Q. J. R. Meteorol. Soc. 2008, 134, 551-561. [CrossRef]

5. Zhang, J.A.; Rogers, R.F.; Nolan, D.S.; Marks, F.D. On the Characteristic Height Scales of the Hurricane Boundary Layer. Mon. Weather Rev. 2011, 139, 2523-2535. [CrossRef]

6. Seidel, D.J.; Ao, C.O.; Li, K. Estimating climatological planetary boundary layer heights from radiosonde observations: Comparison of methods and uncertainty analysis. J. Geophys. Res. 2010, 115, D16113. [CrossRef]

7. Braun, S.; Tao, W.-K. Sensitivity of High-Resolution Simulations of Hurricane Bob (1991) to Planetary Boundary Layer Parameterizations. Mon. Weather Rev. 2000, 128, 3941-3961. [CrossRef]

8. Smith, R.; Thomsen, G. Dependence of tropical-cyclone intensification on the boundary-layer representation in a numerical model. Q. J. R. Meteorol. Soc. 2010, 136, 1671-1685. [CrossRef]

9. Ren, Y.; Zhang, J.A.; Guimond, S.R.; Wang, X. Hurricane Boundary Layer Height Relative to Storm Motion from GPS Dropsonde Composites. Atmosphere 2019, 10, 339. [CrossRef]

10. Holzworth, C.G. Estimates of Mean Maximum Mixing Depths in the Contiguous United States. Mon. Weather Rev. 1964, 92, 235-242. [CrossRef]

11. Beyrich, F. Mixing height estimation from sodar data-A critical discussion. Atmos. Environ. 1997, 31, 3941-3953. [CrossRef]

12. Dupont, E.; Menut, L.; Carissimo, B.; Pelon, J.; Flamant, P. Comparison between the atmospheric boundary layer in Paris and its rural suburbs during the ECLAP experiment. Atmos. Environ. 1999, 33, 979-994. [CrossRef]

13. Smith, A.B.; Katz, R.W. US billion-dollar weather and climate disasters: Data sources, trends, accuracy and biases. Nat. Hazards 2013, 67, 387-410. [CrossRef]

14. Zhang, J.A.; Rogers, R.F.; Reasor, P.D.; Uhlhorn, E.W.; Marks, F.D. Asymmetric Hurricane Boundary Layer Structure from Dropsonde Composites in Relation to the Environmental Vertical Wind Shear. Mon. Weather Rev. 2013, 141, 3968-3984. [CrossRef] 
15. Smith, R.K.; Montgomery, M.T.; Van Sang, N. Tropical cyclone spin-up revisited. Q. J. R. Meteorol. Soc. 2009, $135,1321-1335$. [CrossRef]

16. Kepert, J.D.; Schwendike, J.; Ramsay, H. Why is the Tropical Cyclone Boundary Layer Not "Well Mixed"? J. Atmos. Sci. 2016, 73, 957-973. [CrossRef]

17. Bryan, G.H.; Rotunno, R. The Maximum Intensity of Tropical Cyclones in Axisymmetric Numerical Model Simulations. Mon. Weather Rev. 2009, 137, 1770-1789. [CrossRef]

18. Zawislak, J.; Jiang, H.; Alvey, G.R.; Zipser, E.J.; Rogers, R.F.; Zhang, J.A.; Stevenson, S.N. Observations of the Structure and Evolution of Hurricane Edouard (2014) during Intensity Change. Part I: Relationship between the Thermodynamic Structure and Precipitation. Mon. Weather Rev. 2016, 144, 3333-3354. [CrossRef]

19. Rogers, R.F.; Zhang, J.A.; Zawislak, J.; Jiang, H.; Alvey, G.R.; Zipser, E.J.; Stevenson, S.N. Observations of the Structure and Evolution of Hurricane Edouard (2014) during Intensity Change. Part II: Kinematic Structure and the Distribution of Deep Convection. Mon. Weather Rev. 2016, 144, 3355-3376. [CrossRef]

20. Ooyama, K. Numerical Simulation of the Life Cycle of Tropical Cyclones. J. Atmos. Sci. 1969, 26, 3-40. [CrossRef]

21. Schubert, W.H.; Hack, J.J. Inertial Stability and Tropical Cyclone Development. J. Atmos. Sci. 1982, 39, 1687-1697. [CrossRef]

22. Coulter, R. A Comparison of Three Methods for Measuring Mixing-Layer Height. J. Appl. Meteorol. 1979, 18, 1495-1499. [CrossRef]

23. Lokoshchenko, M. Long-Term Sodar Observations in Moscow and a New Approach to Potential Mixing Determination by Radiosonde Data. J. Atmos. Ocean. Technol. 2002, 19, 1151-1162. [CrossRef]

24. Hock, T.; Franklin, J. The NCAR GPS dropwindesonde. Bull. Am. Meteorol. Soc. 1999, 80, 407-420. [CrossRef]

25. Ratnam, M.V.; Basha, S.G. A robust method to determine global distribution of atmospheric boundary layer top from COSMIC GPS RO measurements. Atmos. Sci. Lett. 2010, 11, 216-222. [CrossRef]

26. Guimond, S.; Tian, L.; Heymsfield, G.; Frasier, S.J. Wind Retrieval Algorithms for the IWRAP and HIWRAP Airborne Doppler Radars with Applications to Hurricanes. J. Atmos. Ocean. Technol. 2014, 31, 1189-1215. [CrossRef]

27. Guimond, S.; Zhang, J.; Sapp, J.; Frasier, S.J. Coherent Turbulence in the Boundary Layer of Hurricane Rita (2005) During an Eyewall Replacement Cycle. J. Atmos. Sci. 2018, 75, 3071-3093. [CrossRef]

28. Kursinski, E.R.; Hajj, G.A.; Schofield, J.T.; Linfield, R.P.; Hardy, K.R. Observing Earth's atmosphere with radio occultation measurements using the Global Positioning System. J. Geophys. Res. Atmos. 1997, 102, 23429-23465. [CrossRef]

29. Steiner, A.K.; Lackner, B.C.; Ladstädter, F.; Scherllin-Pirscher, B.; Foelsche, U.; Kirchengast, G. GPS radio occultation for climate monitoring and change detection. Radio Sci. 2011, 46, RS0D24. [CrossRef]

30. Hajj, G.; Kursinski, R.; Romans, L.J.; Bertiger, W.I.; Leroy, S. A technical description of atmospheric sounding by GPS occultation. J. Atmos. Sol.-Terr. Phys. 2002, 64, 451-469. [CrossRef]

31. Anthes, R.A. Exploring earth's atmosphere with radio occultation: Contributions to weather, climate and space weather. Atmos. Meas. Tech. 2011, 4, 1077-1103. [CrossRef]

32. Schreiner, W.; Sokolovskiy, S.; Hunt, D.; Rocken, C.; Kuo, Y.H. Analysis of GPS radio occultation data from the FORMOSAT3/COSMIC and Metop/GRAS missions at CDAAC. Atmos. Meas. Tech. 2011, 4, 2255-2272. [CrossRef]

33. Chen, S.-Y.; Liu, C.-Y.; Huang, C.-Y.; Hsu, S.-C.; Li, H.-W.; Lin, P.-H.; Cheng, J.-P.; Huang, C.-Y. An analysis study of FORMOSAT7/COSMIC-2 radio occultation data in the troposphere. Remote Sens. 2021, 13, 717. [CrossRef]

34. Ho, S.-P.; Zhou, X.; Shao, X.; Zhang, B.; Adhikari, L.; Kireev, S.; He, Y.; Yoe, J.G.; Xia-Serafino, W.; Lynch, E. Initial Assessment of the COSMIC-2/FORMOSAT-7 Neutral Atmosphere Data Quality in NESDIS/STAR Using In Situ and Satellite Data. Remote Sens. 2020, 12, 4099. [CrossRef]

35. Schreiner, W.S.; Weiss, J.P.; Anthes, R.A.; Braun, J.; Chu, V.; Fong, J.; Hunt, D.; Kuo, Y.-H.; Meehan, T.; Serafino, W.; et al. COSMIC-2 Radio Occultation Constellation: First Results. Geophys. Res. Lett. 2020, 47, e2019GL086841. [CrossRef]

36. Biondi, R.; Ho, S.-P.; Randel, W.; Syndergaard, S.; Neubert, T. Tropical cyclone cloud-top height and vertical temperature structure detection using GPS radio occultation measurements. J. Geophys. Res. Atmos. 2013, 118, 5247-5259. [CrossRef]

37. Biondi, R.; Steiner, A.K.; Kirchengast, G.; Rieckh, T. Characterization of thermal structure and conditions for overshooting of tropical and extratropical cyclones with GPS radio occultation. Atmos. Chem. Phys. 2015, 15, 5181-5193. [CrossRef]

38. Ravindra Babu, S.; Venkat Ratnam, M.; Basha, G.; Krishnamurthy, B.V.; Venkateswararao, B. Effect of tropical cyclones on the tropical tropopause parameters observed using COSMIC GPS RO data. Atmos. Chem. Phys. 2015, 15, 10239-10249. [CrossRef]

39. Lasota, E.; Steiner, A.K.; Kirchengast, G.; Biondi, R. Tropical cyclones vertical structure from GNSS radio occultation: An archive covering the period 2001-2018. Earth Syst. Sci. Data 2020, 12, 2679-2693. [CrossRef]

40. Xie, F.; Wu, D.L.; Ao, C.O.; Mannucci, A.J.; Kursinski, E.R. Advances and limitations of atmospheric boundary layer observations with GPS occultation over southeast Pacific Ocean. Atmos. Chem. Phys. 2012, 12, 903-918. [CrossRef]

41. Basha, G.; Kishore, P.; Ratnam, M.V.; Ravindra Babu, S.; Velicogna, I.; Jiang, J.H.; Ao, C.O. Global climatology of planetary boundary layer top obtained from multi-satellite GPS RO observations. Clim. Dyn. 2018, 52, 2385-2398. [CrossRef]

42. Bonafoni, S.; Biondi, R.; Brenot, H.; Anthes, R. Radio occultation and ground-based GNSS products for observing, understanding and predicting extreme events: A review. Atmos. Res. 2019, 230, 104624. [CrossRef]

43. Ao, O.; Hajj, G.; Meehan, T.; Dong, D.; Iijima, B.; Mannucci, A.; Kursinski, R. Rising and Setting GPS Occultations by Use of Open-Loop Tracking. J. Geophys. Res. 2009, 114. [CrossRef] 
44. Ho, S.-P.; Anthes, R.A.; Ao, C.O.; Healy, S.; Horanyi, A.; Hunt, D.; Mannucci, A.J.; Pedatella, N.; Randel, W.J.; Simmons, A.; et al. The COSMIC/FORMOSAT-3 Radio Occultation Mission after 12 Years: Accomplishments, Remaining Challenges, and Potential Impacts of COSMIC-2. Bull. Am. Meteorol. Soc. 2020, 101, E1107-E1136. [CrossRef]

45. Hordyniec, P.; Kuleshov, Y.; Choy, S.; Norman, R. Observation of Deep Occultation Signals in Tropical Cyclones with COSMIC-2 Measurements. IEEE Geosci. Remote Sens. Lett. 2021, 1-5. [CrossRef]

46. Sokolovskiy, S.V.; Rocken, C.; Lenschow, D.H.; Kuo, Y.H.; Anthes, R.A.; Schreiner, W.S.; Hunt, D.C. Observing the moist troposphere with radio occultation signals from COSMIC. Geophys. Res. Lett. 2007, 34, L18802. [CrossRef]

47. Basha, G.; Ratnam, M.V. Identification of atmospheric boundary layer height over a tropical station using high-resolution radiosonde refractivity profiles: Comparison with GPS radio occultation measurements. J. Geophys. Res. Atmos. 2009, 114. [CrossRef]

48. Yan, S.; Xiang, J.; Du, H. Determining Atmospheric Boundary Layer Height with the Numerical Differentiation Method Using Bending Angle Data from COSMIC. Adv. Atmos. Sci. 2019, 36, 303-312. [CrossRef]

49. Peevey, T.R.; Atlas, R.; Hoffman, R.N.; Casey, S.P.F.; Cucurull, L.; Kren, A.C.; Mueller, M.J. Impact of Refractivity Profiles from a Proposed GNSS-RO Constellation on Tropical Cyclone Forecasts in a Global Modeling System. Mon. Weather Rev. 2020, 148, 3037-3057. [CrossRef]

50. Smith, E.K.; Weintraub, S. The Constants in the Equation for Atmospheric Refractive Index at Radio Frequencies. Proc. IRE 1953, 50, 1035-1037. [CrossRef]

51. Melbourne, W.G.; Davis, E.S.; Duncan, C.B. The Application of Spaceborne GPS to Atmospheric Limb Sounding and Global Change Monitoring; NASA Jet Propulsion Laboratory: Pasadena, CA, USA, 1994; pp. 4-18.

52. Stull, R.B. An Introduction to Boundary Layer Meteorology, 1st ed.; Springer: Dordrecht, The Netherlands, 1988 ; p. I-1.

53. Brunner, L.; Steiner, A.K.; Scherllin-Pirscher, B.; Jury, M.W. Exploring atmospheric blocking with GPS radio occultation observations. Atmos. Chem. Phys. 2016, 16, 4593-4604. [CrossRef] 